\title{
Magnetic properties of natural pyrrhotite Part I: Behaviour of initial susceptibility and saturation-magnetization-related rock-magnetic parameters in a grain-size dependent framework
}

\author{
M.J. Dekkers \\ Paleomagnetic Laboratory 'Fort Hoofddijk', University of Utrecht, Budapestlaan 17, 3584 CD Utrecht (The Netherlands)
}

(Received June 9, 1987; revision accepted November 7, 1987)

\begin{abstract}
Dekkers, M.J., 1988. Magnetic properties of natural pyrrhotite Part I: Behaviour of initial susceptibility and saturation-magnetization-related rock-magnetic parameters in a grain-size dependent framework. Phys. Earth Planet. Inter., 52: 376-393.

The grain-size dependence of the initial susceptibility $\left(X_{\text {in }}\right)$, saturation magnetization $\left(J_{\mathrm{s}}\right)$, saturation remanence $\left(J_{\mathrm{rs}}\right)$, coercive force $\left(H_{\mathrm{c}}\right)$, remanent coercive force $\left(H_{\mathrm{cr}}\right)$ and remanent acquisition coercive force $\left(H_{\mathrm{cr}}\right)$, is reported for four natural pyrrhotites in a grain-size range from $250 \mu \mathrm{m}$ down to $<5 \mu \mathrm{m}$. $X_{\text {in }}$ decreases with decreasing grain size (range $7 \times 10^{-5}-1 \times 10^{-5} \mathrm{~m}^{3} \mathrm{~kg}^{-1}$ ); $H_{\mathrm{c}}, H_{\mathrm{cr}}$ and $H_{\mathrm{cr}}$ all increase with decreasing grain size (ranges respectively $7-80,8-85$ and 14-80 $\left.\mathrm{kA} \mathrm{m}^{-1}\right)$. The magnitudes of $J_{\mathrm{s}}\left(8.9-16.7 \mathrm{~A} \mathrm{~m}^{2} \mathrm{~kg}^{-1}\right)$ and $J_{\mathrm{rs}}\left(2.0-6.0 \mathrm{~A} \mathrm{~m}^{2} \mathrm{~kg}^{-1}\right)$ correspond with the trend indicated by the microprobe analysis ( 47.8 down to 46.9 at.\% equivalent $\mathrm{Fe}$ ). $J_{\mathrm{rs}}$ shows a maximum in the pseudo-single domain region (range 2.0-6.0 A m $\mathrm{kg}^{-1}$ ). $J_{\mathrm{s}}$ shows a marked decrease for the finest grain-size fractions. Typical for pyrrhotite are a large $H_{\mathrm{c}} / H_{\mathrm{cr}}$ ratio and a $J_{\mathrm{rs}} / X_{\text {in }}$ ratio which is larger than $H_{\mathrm{cr}}$. When the presence of pyrrhotite has been established in a sample, its grain size is preferable determined by the $H_{\mathrm{cr}}$ trend because pyrrhotite compositional differences hardly show up in this trend.
\end{abstract}

\section{Introduction}

The solid solution series of $\mathrm{Fe}-\mathrm{S}$ compounds of composition $\mathrm{Fe}_{1-x} \mathrm{~S}$, with $x$ varying between 0 and 0.13 , is usually referred to as pyrrhotite. Nearly stoichiometric FeS is known as troilite (an Fe-deficiency between 0.003 and 0.006 formula units is reported; cf., Ward, 1970). Though the pyrrhotite potential of carrying a remanent magnetization has been well established for a long time (e.g., Bertaut, 1953), pyrrhotite was for a long time regarded as a magnetic mineral of minor paleomagnetic importance, because it was believed to occur almost exclusively in association with sulphidic ores. However, the existence of pyrrhotite without spatial relation to these ores is increasingly reported. It is nowadays known from various types of igneous rocks (e.g., Soffel, 1977), in metamorphic rocks (e.g., Carpenter, 1974; Rochette, 1987) and also in sediments (e.g., Kligfield and Channell, 1981; Freeman, 1986). This considerably increases the paleomagnetic significance of pyrrhotite.

The pyrrhotite crystal structure consists of alternating $\mathrm{Fe}$ and $\mathrm{S}$ layers, based on the NiAs crystal structure. The atoms in each Fe-layer are ferromagnetically coupled; antiferromagnetic coupling exists with each neighbouring Fe-layer. The crystallographic $C$-axis is the hard axis of magnetization; the easy directions are confined to the basal plane which shows a (strong) trigonal anisotropy (Bin and Pauthenet, 1963). The initial susceptibility is extremely anisotropic with magnetite-like figures in the basal plane and paramagnet-like figures along the hard axis (Schwarz, 1975). All $\mathrm{Fe}$ in pyrrhotite is $\mathrm{Fe}^{2+}$ and the valence 
of $S$ is $<2$ (Ward, 1970). Pyrrhotite contains a certain amount of vacancies depending on its chemical composition. The most Fe-deficient pyrrhotite $\left(\mathrm{Fe}_{7} \mathrm{~S}_{8}\right)$ has a monoclinic crystal structure; the more Fe-rich pyrrhotites are hexagonal.

Since the vacancies show some tendency to concentrate in alternate Fe-layers (Goodenough, 1978), the vacancy distribution has direct consequences for the pyrrhotite magnetic properties. The vacancy distribution can be described by socalled superstructures. The more common integral superstructures are the $4 \mathrm{C}$ superstructure for the ferrimagnetic monoclinic $\mathrm{Fe}_{7} \mathrm{~S}_{8}$ (Bertaut, 1953) and $5 \mathrm{C}, 11 \mathrm{C}$ and $6 \mathrm{C}$ superstructures for the antiferromagnetic hexagonal pyrrhotite (e.g., Fleet and MacRae, 1969; Morimoto et al., 1970, 1975a). Also, non-integral superstructures, previously thought to occur only at elevated temperatures, are reported at ambient temperatures (e.g., Morimoto et al., 1975a, 1975b).

Natural pyrrhotite usually consists of mixtures of superstructures of monoclinic and hexagonal pyrrhotite (e.g., Arnold, 1967), which results in an intermediate overall composition. Different superstructures can coexist within a single pyrrhotite crystal. This was detected with $\mathrm{X}$-ray methods (e.g., Morimoto et al., 1975a, 1975b), with highresolution electron microscopy (e.g., Morimoto et al., 1974; Pierce and Buseck, 1974) or made visible microscopically by applying etching techniques (e.g., Naldrett and Kullerud, 1967).

The $4 \mathrm{C}$ pyrrhotite saturation magnetization is reported to be $20 \mathrm{~A} \mathrm{~m}^{2} \mathrm{~kg}^{-1}$ (e.g., Schwarz and Vaughan, 1972; Halgedahl and Fuller, 1981). Besnus and Meyer (1964) reported a saturation magnetization of $22.5 \mathrm{~A} \mathrm{~m}^{2} \mathrm{~kg}^{-1}$ for an unspecified natural pyrrhotite crystal. The saturation magnetization of mixed pyrrhotite depends on the content of 4C pyrrhotite present. Domain observations (Soffel, 1977, 1981; Halgedahl and Fuller, 1981) showed that $180^{\circ}$ domains walls prevail in the pyrrhotite domain structure. Grains of $\sim 100 \mu \mathrm{m}$ size showed true multidomain (MD) behaviour; the range between $2-3$ and $40 \mu \mathrm{m}$ is regarded as a pseudo-single domain (PSD) region. The SD/PSD border is found between 1.5 and $2 \mu \mathrm{m}$ (Soffel, 1977). Clark (1984) calculated $3 \mu \mathrm{m}$ for the SD/PSD transition. The coercive force for a large
MD crystal is $9.0 \mathrm{kA} \mathrm{m}^{-1}$ (Halgedahl and Fuller, 1981) and for the PSD range $14.3 \mathrm{kA} \mathrm{m}^{-1}$ (Soffel, 1981). The ratio of the saturation remanence and saturation magnetization for the larger MD crystal is reported to be 0.14 (Halgedahl and Fuller, 1981). Clark (1984) described hysteresis properties of sized monophase monoclinic $4 \mathrm{C}$ pyrrhotite fractions in a grain-size range of $83 \mu \mathrm{m}$ down to $<3 \mu \mathrm{m}$. He found a steadily increasing coercive force $\left(10.7-73.2 \mathrm{kA} \mathrm{m}^{-1}\right)$, remanent coercive force (14.7-113.4 $\mathrm{kA} \mathrm{m}^{-1}$ ) and remanent acquisition coercive force $\left(21.5-106.6 \mathrm{kA} \mathrm{m}^{-1}\right)$ with decreasing grain size. The initial susceptibility decreases with decreasing grain size, whereas the saturation remanence increases with decreasing grain size down to $15 \mu \mathrm{m}$ and subsequently decreases slightly with a further decrease in grain size.

Grain-size dependence of these and other rock-magnetic parameters for pyrrhotite is poorly documented at present: Clark's (1984) study is the only one which reports grain-size dependent trends in pyrrhotite. The present study reports the grain-size dependence of the saturation magnetization $\left(J_{s}\right)$, saturation remanence $\left(J_{\mathrm{rs}}\right)$, the initial specific susceptibility $\left(X_{\mathrm{in}}\right)$, the coercive force $\left(H_{\mathrm{c}}\right)$ and remanent coercive force $\left(H_{\mathrm{cr}}\right)$ as well as the remanent acquisition coercive force $\left(H_{\mathrm{cr}^{\prime}}\right)$ in a grain-size range from $250 \mu \mathrm{m}$ down to $<5 \mu \mathrm{m}$. Therefore a series of artificial samples using the methodology of Dankers $(1978,1981)$ and Hartstra (1982a) was prepared containing homogeneously dispersed natural pyrrhotite of a well-defined grain-size range.

\section{Sample description}

Pyrrhotite, belonging to various geologic associations, was selected for investigation from four locations. It was sampled at Isola di Vocca (Ivrea Zone, Italy) from an orthomagmatic disseminated $\mathrm{Fe}-\mathrm{Ni}-\mathrm{Cu}$ ore in a noritic-gabbroitic complex (cf., Rivalenti, 1979; Natale and Zuchetti, 1979; Bigioggero et al., 1979; Ferrario et al., 1983); at Temperino (Tuscany, Italy) from a pyrometasomatic pyrrhotite-pyrite-chalcopyrite ore zone (cf., Bodechtel, 1965, 1968); and at Ortano and Ginevro (both on Elba, Italy) from reheated, originally volcano-sedimentary, pyrite-hematite 
TABLE IA

Average pyrrhotite composition determined by microprobe analyses

\begin{tabular}{|c|c|c|c|c|c|c|c|c|c|c|c|c|}
\hline & \multicolumn{3}{|l|}{ TTE } & \multicolumn{3}{|l|}{ EOR } & \multicolumn{3}{|l|}{ DIS } & \multicolumn{3}{|l|}{ EGI } \\
\hline & Av. & sd & Norm. & Av. & sd & Norm. & Av. & sd & Norm. & Av. & sd & Norm. \\
\hline S & 53.03 & 0.19 & 39.27 & 53.14 & 0.35 & 39.39 & 52.25 & 0.30 & 38.47 & 52.85 & 0.23 & 39.04 \\
\hline $\mathrm{Fe}$ & 46.76 & 0.18 & 60.32 & 46.70 & 0.36 & 60.30 & 47.41 & 0.29 & 60.80 & 46.95 & 0.34 & 60.41 \\
\hline Mn & 0.02 & 0.03 & 0.02 & 0.01 & 0.02 & 0.01 & 0.01 & 0.02 & 0.01 & 0.02 & 0.03 & 0.02 \\
\hline $\mathrm{Ni}$ & 0.17 & 0.14 & 0.23 & 0.14 & 0.10 & 0.19 & 0.39 & 0.11 & 0.52 & 0.27 & 0.08 & 0.41 \\
\hline $\mathrm{Cu}$ & 0.06 & 0.09 & 0.09 & 0.03 & 0.05 & 0.04 & 0.05 & 0.06 & 0.07 & 0.04 & 0.06 & 0.06 \\
\hline $\mathrm{Zn}$ & 0.04 & 0.08 & 0.06 & 0.04 & 0.08 & 0.06 & 0.08 & 0.13 & 0.12 & 0.04 & 0.08 & 0.06 \\
\hline Total & 100.08 & & 99.99 & 100.06 & & 99.99 & 100.19 & & 99.99 & 100.18 & & 100.00 \\
\hline
\end{tabular}

Analyses were carried out with a TPD (Technisch Physische Dienst) microprobe fitted with a TRACOR Northern Energy Dispersive (ED) system. Operating conditions were $15 \mathrm{keV}$ and 2-3 nA. ZAF matrix correction was applied. Av. is average atom percentage; sd is standard deviation; Norm. is normalized weight percentage. Most spots contained no detectable $\mathrm{Mn}, \mathrm{Cu}$ and $\mathrm{Zn}$. Ni is enhanced in the DIS pyrrhotite and slightly raised in EGI pyrrhotite; in the others its amount is insignificant. TTE 32 spot analyses; EOR 21 analyses; DIS 16 analyses; EGI 16 analyses. $\mathrm{Fe}_{7} \mathrm{~S}_{8}$ contains 53.33 at.\% $\mathrm{S}\left(4 \mathrm{C}\right.$ superstructure); $\mathrm{Fe}_{8} \mathrm{~S}_{9} 52.94$ at.\% S; $\mathrm{Fe}_{9} \mathrm{~S}_{10} 52.63$ at.\% $\mathrm{S}(5 \mathrm{C}) ; \mathrm{Fe}_{10} \mathrm{~S}_{11} 52.38$ at.\% S (11C); and $\mathrm{Fe}_{11} \mathrm{~S}_{12} 52.17$ at.\% S (6C).

ores (cf., Bodechtel, 1965; Dimanche, 1971; Waldeck, 1977). All samples contained well-crystalline pyrrhotite. A concise description of each pyrrhotite sample is given below; for a more detailed overview the reader is referred to Dekkers (1988). Chemical and X-ray diffraction data of the

\section{TABLE IB}

Pyrrhotite trace element content (wet chemical) in ppm

\begin{tabular}{lllll}
\hline & TTE & EOR & DIS $^{\text {a }}$ & EGI \\
\hline $\mathrm{Co}$ & 215 & 320 & 755 & 440 \\
$\mathrm{~Pb}$ & $<\mathrm{d} l$ & $<\mathrm{dl}$ & $<\mathrm{dl}$ & $<\mathrm{dl}$ \\
$\mathrm{Ba}$ & $<\mathrm{dl}$ & $<\mathrm{dl}$ & $<\mathrm{dl}$ & $<\mathrm{dl}$ \\
$\mathrm{Mn}$ & 430 & 85 & 815 & 285 \\
$\mathrm{~V}$ & $<\mathrm{dl}$ & $<\mathrm{dl}$ & 528 & $<\mathrm{dl}$ \\
$\mathrm{Zn}$ & 795 & $<\mathrm{dl}$ & 325 & $<\mathrm{dl}$ \\
$\mathrm{Cu}$ & $<\mathrm{dl}$ & 715 & 3220 & 835 \\
$\mathrm{Ni}$ & 85 & 130 & 2430 & 205 \\
$\mathrm{Cr}$ & $<\mathrm{dl}$ & $<\mathrm{dl}$ & $<\mathrm{dl}$ & $<\mathrm{dl}$ \\
\hline
\end{tabular}

a The DIS sample contains 37\% non-pyrrhotite minerals (almost exclusively silicates, $>99 \%$ ). Analyses were carried out by the Service Laboratory, Institute of Earth Sciences, State University of Utrecht. All elements were analysed with ICPES (Induction Coupled Plasma Emission Spectrometry); the detection limit (dl) for each element is $-10 \mathrm{ppm}$. Comparison of Tables $1 \mathrm{~A}$ and $1 \mathrm{~B}$ shows that the number of spots in the MP analyses is too low to obtain reasonable estimates for elements which are below 0.3 at.\%. pyrrhotites and the intergrowth amount of each final grain-size fraction are compiled in Tables I-III.

\subsection{Isola di Vocca (abbreviation DIS)}

The DIS pyrrhotite belongs to a pyrrhotitepentlandite-chalcopyrite ore assemblage with minor mackinawite, magnetite, ilmenite and sphalerite. The host-rock mineralogy is dominated by olivine and pyroxenes. Magnetite occurs only accessory $(<2 \%)$ in the pyrrhotite concentrate; pentlandite and chalcopyrite are hardly observed. The grains in the final fractions are approximately equidimensional. The larger grain-size fractions ( $>30 \mu \mathrm{m})$ consist of pyrrhotite intergrown with silicates.

\subsection{Temperino (abbreviation TTE)}

The TTE pyrrhotite is concentrated from a pyrite/pyrrhotite skarn from a complex $\mathrm{Cu}-\mathrm{Zn}$ bearing ore zone. Pyrrhotite and pyrite occur in a long prismatic habit in sheaf-like aggregates intergrown predominantly with ilvaite. The width of the sulphide parts is a few hundred micrometers. The pyrrhotite concentrates contain equidimensional grains. Intergrowths are rare; no magnetite is identified. 
TABLE II

Unit cell dimensions of the pyrrhotite samples

\begin{tabular}{lcccccc}
\hline & TTE 4C & \multicolumn{1}{c}{ EOR 4C } & \multicolumn{1}{c}{ DIS 4C } & \multicolumn{1}{c}{ DIS 5C } & \multicolumn{1}{c}{ DIS 6C } & \multicolumn{1}{c}{ EGI 4C } \\
\hline$a$-Axis & $11.840 \pm 0.007$ & $11.818 \pm 0.007$ & $11.847 \pm 0.007$ & $6.846 \pm 0.003$ & $6.852 \pm 0.004$ & $11.843 \pm 0.007$ \\
$b$-Axis & $6.845 \pm 0.004$ & $6.835 \pm 0.004$ & $6.849 \pm 0.004$ & $6.846 \pm 0.003$ & $6.852 \pm 0.004$ & $6.850 \pm 0.004$ \\
$c$-Axis & $22.706 \pm 0.013$ & $22.656 \pm 0.013$ & $22.669 \pm 0.013$ & $28.504 \pm 0.014$ & $34.131 \pm 0.018$ & $22.720 \pm 0.013$ \\
Volume & $1840 \pm 1$ & $1830 \pm 1$ & $1839 \pm 1$ & $1156 \pm 1$ & $1387 \pm 1$ & $1843 \pm 1$ \\
$\alpha$ & $90.00 \pm 0.015$ & $90.00 \pm 0.014$ & $90.00 \pm 0.015$ & $90.00 \pm 0.000$ & $90.00 \pm 0.000$ & $90.00 \pm 0.015$ \\
$\beta$ & $90.410 \pm 0.000$ & $90.409 \pm 0.000$ & $90.369 \pm 0.000$ & $90.00 \pm 0.000$ & $90.00 \pm 0.000$ & $90.369 \pm 0.000$ \\
$\gamma$ & $90.00 \pm 0.000$ & $90.00 \pm 0.000$ & $90.00 \pm 0.000$ & $120.00 \pm 0.013$ & $120.00 \pm 0.014$ & $90.00 \pm 0.000$ \\
NiAs cell & & & & & & 3.43 \\
$a$-Axis & 3.42 & 3.42 & 3.42 & 3.42 & 5.69 & 5.68 \\
$c$-Axis & 5.68 & 5.66 & 5.67 & 5.70 & & \\
\hline
\end{tabular}

Cell dimensions are in $\AA$; cell volumes in cubic $\AA$. The indicated errors are standard deviations. $4 \mathrm{C}, 5 \mathrm{C}$ and $6 \mathrm{C}$ refer to the pyrrhotite superstructure. In hexagonal pyrrhotite the (408) and (408) reflections coincide and have a $d$-value of $\sim 2.06 \AA$, depending on the pyrrhotite chemistry. In monoclinic 4C pyrrhotite the (408) and (408) reflections show up as a doublet at $d \sim 2.06 \AA$ and $d \sim 2.04 \AA$. Both reflections of this doublet are of similar intensity in TTE, EOR and EGI pyrrhotite; the second (monoclinic) reflection is much more weakly developed in the DIS pyrrhotite sample. This indicates that there is least ferrimagnetic $4 \mathrm{C}$ phase in the last sample. A distinct lower susceptibility of the DIS pyrrhotite, observed during the magnetic separation step, is in agreement with the $\mathrm{X}$-ray determination.

\subsection{Ortano (abbreviation EOR)}

Pyrrhotite, collected from the mine dumps at Ortano on the eastern coast of Elba, is intergrown with epidote, ilvaite and minor hedenbergite. The pyrrhotite is well developed in the skarn. The separated grain-size fractions consist of equi- dimensional pyrrhotite grains. The intergrowth amount is subordinate; no magnetite is identified.

\subsection{Ginevro (abbreviation EGI)}

Pyrrhotite occurs as a minor mineral in a magnetite/hedenbergite skarn at Ginevro on the

TABLE III

Amount of intergrowths, pyrrhotite and magnetite contents of the pyrrhotite grain-size fractions determined by point-counting (reflected light microscopy)

\begin{tabular}{|c|c|c|c|c|c|c|c|c|c|c|c|c|}
\hline & TTE & & & EOR & & & DIS & & & EG & & \\
\hline Fraction & po & $\mathrm{mg}$ & int. & po & $\mathrm{mg}$ & int. & po & $\mathrm{mg}$ & int. & po & mg & int. \\
\hline $250-150$ & $>99$ & bd & bd & $>99$ & bd & $b d$ & 31 & $b d$ & 100 & 78 & 22 & bd \\
\hline $150-100$ & $>99$ & bd & bd & $>99$ & bd & bd & 48 & bd & 90 & 78 & 22 & bd \\
\hline $100-75$ & $>99$ & bd & bd & $>99$ & bd & bd & 72 & bd & 50 & 80 & 20 & bd \\
\hline $75-55$ & $>99$ & bd & bd & $>99$ & bd & bd & 63 & bd & 50 & 81 & 19 & bd \\
\hline $55-40$ & $>99$ & bd & bd & $>99$ & bd & bd & 70 & bd & 30 & 81 & 19 & bd \\
\hline $40-30$ & $>99$ & bd & bd & $>99$ & bd & bd & 88 & bd & 10 & 86 & 14 & bd \\
\hline $30-25$ & $>99$ & bd & bd & $>99$ & bd & bd & 94 & bd & $<5$ & 86 & 14 & bd \\
\hline $25-20$ & $>99$ & bd & bd & $>99$ & bd & bd & 96 & 2 & bd & 84 & 16 & bd \\
\hline $20-15$ & $>99$ & bd & bd & 92 & bd & bd & 97 & 1 & bd & 92 & 8 & bd \\
\hline $15-10$ & 95 & bd & bd & 80 & bd & bd & 90 & 2 & bd & 83 & 9 & bd \\
\hline $10-5$ & 65 & bd & bd & 70 & bd & bd & 59 & 1 & bd & 78 & 6 & bd \\
\hline$<5$ & 60 & bd & bd & 60 & bd & bd & 57 & bd & bd & 54 & 3 & bd \\
\hline
\end{tabular}

Volume percentages; grain sizes in $\mu \mathrm{m}$; po is pyrrhotite; $\mathrm{mg}$ is magnetite; int. is intergrowth; all in percentages; bd is below detection limit $(<\sim 1 \%)$. The percentages refer to the total sample, in the fine grain-size fractions silicate minerals remain present. The intergrowth percentage refers to the amount of pyrrhotite grains which are intergrown with silicate minerals. 
south-eastern coast of Elba. Pyrrhotite-rich parts of the skarn zone were sampled from the mine dumps. The final grain-size fractions consist of a mixture of equidimensional pyrrhotite and magnetite grains. They occur predominantly as separate monomineralic grains; the magnetite content decreases with decreasing grain size from $25 \mathrm{wt} . \%$ down to $\sim 5 \mathrm{wt} . \%$.

\subsection{Preparation of the artificial specimens}

The pyrrhotite grain-size fractions were obtained by subsequent crushing, sieving, magnetic separation and ultrasonic microprecision sieving. Crushing was performed in a $\mathrm{Cu}$ mortar. The first sieving step was performed to optimize the magnetic separation step. The ASTM sieving set was used; wet sieving was performed with acetone as the flushing fluid. The coarse grain-size fractions $(>37 \mu \mathrm{m})$ of the TTE, EOR and EGI samples were separated by moving a hand-magnet quickly bakc and forth over the sample at a few centimetres distance. The DIS fractions were separated magnetically with a Frantz-isodynamic separator adapted for separation in a liquid medium (ethanol was used). The fine grain-size fractions $(<37 \mu \mathrm{m})$ were all separated with the aid of the modified Frantz-isodynamic separator; an input of the grains in suspended form was created (Dekkers et al., in preparation). Microprecision sieving was carried out in an ultrasonic bath to remove fine, magnetically adhered pyrrhotite particles from coarse ones. Each separation step was carried out as much as possible in an inert atmosphere, because pyrrhotite tarnishes easily in moist air. This applies especially for the microprecision sieving step: when microsieving in contact with air pyrrhotite grains oxidize instantaneously. The grains disintegrate, colouring the acetone red-brown. When sieving was performed in an inert atmosphere, no red-brown colouring of the acetone occurs and the pyrrhotite grains retain their typical brassy colour. After the separation procedure, the grain-size fractions were stored in an Ar atmosphere.

The results of the magnetic separation were checked optically (transmitted and reflected light) and with X-ray diffraction; the grain-size ranges were controlled optically (transmitted light). The grain-size fractions were homogeneously dispersed in an epoxy resin matrix (Araldite D-hardener HY 956, Ciba-Geigy) or in a quartz/bassanite matrix (CM Löt soldering investment used for dental metalwork). Susceptibility measurements were corrected for the diamagnetic matrix moment; no correction had to be made for the remanent magnetization of both matrices. Approximately 100 $\mathrm{mg}$ of pyrrhotite was put in standard-sized paleomagnetic specimens ( $0.2 \%$ by volume). Samples for high-field susceptibility measurements were sized down on a lathe from epoxy resin cylinders initially of $1 \mathrm{~cm}$ diameter and $1 \mathrm{~cm}$ height to cylinders of $4.5 \mathrm{~mm}$ diameter and $5 \mathrm{~mm}$ height. Each final cylinder contained some $5 \mathrm{mg}$ pyrrhotite ( $2 \%$ by volume).

\subsection{Instrumentation for the magnetic measurements}

Initial susceptibility was measured with a Jelinek KLY-1 susceptibility bridge. Acquisition curves of the isothermal remanent magnetization (RA curves) in fields up to $1600 \mathrm{kA} \mathrm{m}^{-1}$ (2 T) were determined with a Förster fluxgate magnetometer type 1.107 , which was calibrated with an astatic magnetometer. Hysteresis loops in a 240 $\mathrm{kA} \mathrm{m}^{-1}$ field $(0.3 \mathrm{~T})$ were determined by measuring the imbalance of a pair of coils, one of which contained the specimen. Measurements were carried out using an ac field. The determinations mentioned so far were carried out at the Paleomagnetic Laboratory 'Fort Hoofddijk' (University of Utrecht, The Netherlands).

A field of only $240 \mathrm{kA} \mathrm{m}^{-1}$ is too small to obtain correct figures for the pyrrhotite saturation magnetization. Therefore magnetization curves were determined in fields up to $1200 \mathrm{kA} \mathrm{m}^{-1}(15$ T). Measurements in fields up to $1040 \mathrm{kA} \mathrm{m}^{-1}$ (1.3 T) were done with a vibrating sample magnetometer (Foner type); in higher fields a ballistic magnetometer was employed. These high-field measurements were carried out at the High Field Magnet Laboratory at the Department of Physics, University of Nijmegen (The Netherlands). 


\section{Results}

\subsection{Susceptibility measurements}

The susceptibility measurements were corrected for the diamagnetic moment of the matrix. Partial hysteresis loops in $240 \mathrm{kA} \mathrm{m}^{-1}$ fields (Fig. 1A) reveal that only the coarse grain-size fractions (from the 75-55 $\mu \mathrm{m}$ fraction upwards) show a reversible magnetization behaviour in the highest field strengths reached by this low-field equipment. Finer grain-size fractions do not show such be-
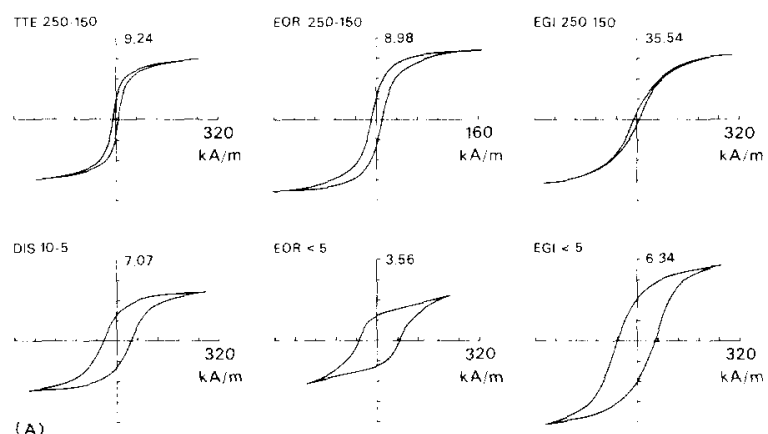

(A)

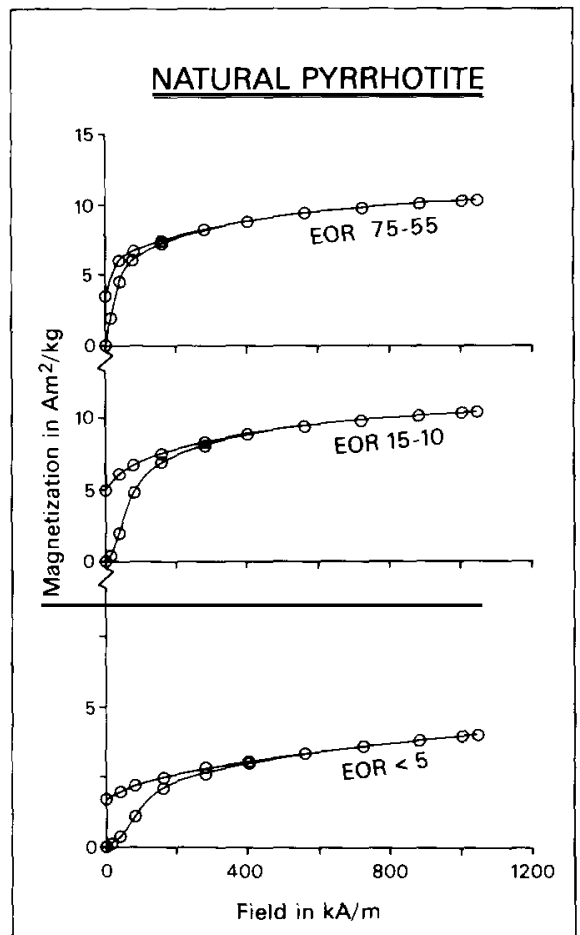

(B)

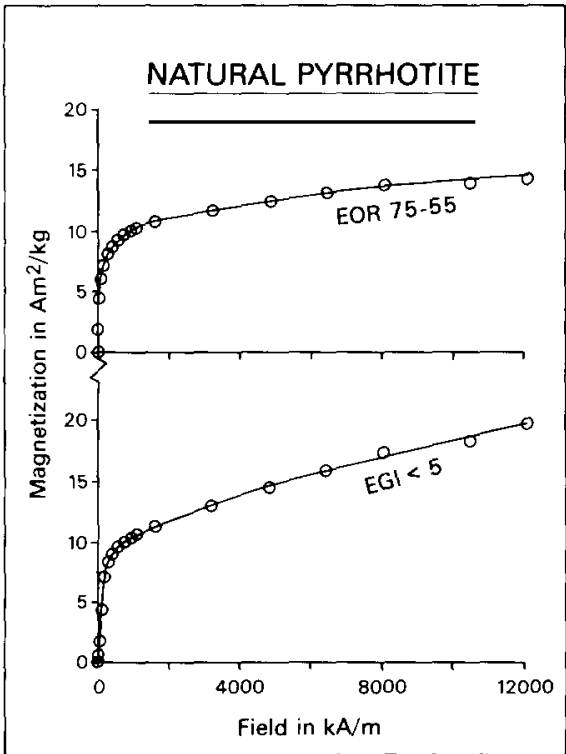

(C)

Fig. 1. (A) Partial hysteresis loops in $160 \mathrm{kA} \mathrm{m}^{-1}(0.2 \mathrm{~T})$ or $240 \mathrm{kA} \mathrm{m}^{-1}(0.3 \mathrm{~T})$ fields. The coarse grain-size fractions already behave reversibly in these small fields. The numbers on the ordinates refer to the magnetization in $\mathrm{A} \mathrm{m}^{2} \mathrm{~kg}^{-1}$. (B) Magnetization curves in fields up to $1040 \mathrm{kA} \mathrm{m}^{-1}(1.3 \mathrm{~T})$. The fine grain-size fractions show reversible hysteresis behaviour in fields above $800 \mathrm{kA} \mathrm{m}^{-1}(1 \mathrm{~T})$. (C) Magnetization curve in fields up to $12000 \mathrm{kA} \mathrm{m}^{-1}(15 \mathrm{~T})$. The coarse grain-size fractions tend to be saturated in this field, whereas the magnetization of the fine grain-size fractions still increases. The magnetizations are corrected for the diamagnetic matrix moment. 


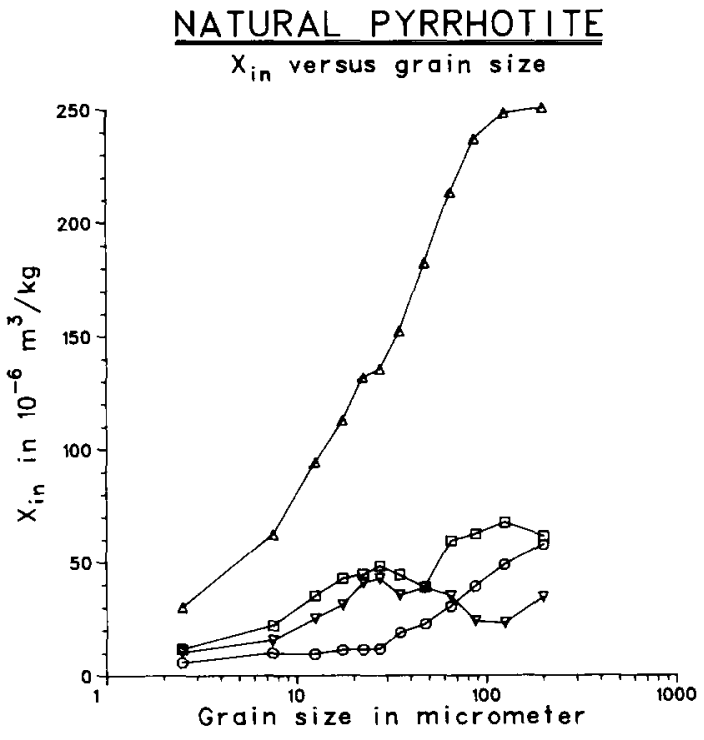

Fig. 2. $X_{\text {in }}$ versus grain size. $\square$, TTE pyrrhotite; $\bigcirc$, EOR pyrrhotite; $\Delta$, EGI pyrrhotite; and $\nabla$, DIS pyrrhotite. The higher $X_{\text {in }}$ of the EGI fractions is caused by their magnetite content.

haviour in fields up to $240 \mathrm{kA} \mathrm{m}^{-1}$. The field strength above which reversible behaviour is observed increases with decreasing grain size. For the $<5 \mu \mathrm{m}$ fractions this field is some $800 \mathrm{kA}$ $\mathrm{m}^{-1}$ (Fig. 1B). Hence, such fields are required for a proper determination of the coercive force.

In extremely small applied fields the movement of the spontaneous magnetization from one easy direction to a more favourably positioned one is fairly difficult, as is indicated by the onset of the magnetization curves (Fig. 1B) and the low initial susceptibility (Fig. 2, Table IV). Domain walls move relatively easily in pyrrhotite in somewhat larger applied fields, as is indicated by the steep rise of the magnetization curves. In high applied fields the spontaneous magnetization is pulled out of the basal plane. This is opposed by a strong magnetocrystalline anisotropy. Large fields are required to saturate a set of randomly distributed pyrrhotite grains (Fig. 1C).

Hysteresis loops of pyrrhotite are characterized by steeply rising branches in small fields and much less steep continuations in higher fields leading to a more or less rectangular curve (Fig. 1A). Pyrrhotite hysteresis loops are much more rectangular than magnetite hysteresis loops: the branches of the hysteresis loop of the EGI 250-150 $\mu \mathrm{m}$ fraction containing $25 \mathrm{wt} . \%$ magnetite (as separate monomineralic grains) are much more gently increasing and decreasing with the external field than loops of samples without magnetite containing the same grain-size range (e.g., TTE 250-150 $\mu \mathrm{m}$ and EOR 250-150 $\mu \mathrm{m}$ ).

The initial susceptibility $\left(X_{\text {in }}\right)$ decreases with decreasing grain size (Fig. 2, Table IV). Similar grain-size fractions of the different pyrrhotite samples have initial susceptibilities of the same order. The much larger $X_{\text {in }}$ of the EGI samples is due to their magnetite content. The much more pronounced decreasing $X_{\text {in }}$ trend with grain size in the EGI pyrrhotite fractions is also caused by a decreasing magnetite content with smaller grain size (cf., Table III). Figures for the pyrrhotite initial susceptibility are somewhat lower than Clark's (1984) figures for pure ferrimagnetic 4C pyrrhotite. The more or less constant $X_{\text {in }}$ in the DIS fraction for grain sizes $>30 \mu \mathrm{m}$ is due to the presence of ubiquitous silicate intergrowths in these coarse fractions limiting the size of the pyrrhotite parts in these grains to $-30 \mu \mathrm{m}$.

The susceptibility of the hard axis, derived from the high-field parts of the magnetization curves, is for EGI $34 \times 10^{-8}$, for TTE $38 \times 10^{-8}$, for EOR $38 \times 10^{-8}$ and for DIS pyrrhotite $32 \times 10^{-8}$ (all figures are in $\mathrm{m}^{3} \mathrm{~kg}^{-1}$ ). These figures are of the same order as those determined by Schwarz and Vaughan (1972).

The saturation magnetization $\left(J_{\mathrm{s}}\right)$ is approximately grain-size independent (Fig. 3, Table IV) with a tendency to decrease with decreasing grain size. In the finest grain-size fractions a clear $J_{\mathrm{s}}$ decrease is observed. A slightly decreasing $J_{\mathrm{s}}$ with decreasing grain size is reported for magnetite by Mauritsch et al. (1987).

TTE pyrrhotite has the highest average $J_{\mathrm{s}}$ $\left(\sim 16.7 \mathrm{~A} \mathrm{~m}^{2} \mathrm{~kg}^{-1}\right)$, followed by EOR and EGI pyrrhotite (respectively 11.5 and $\sim 12.6 \mathrm{~A} \mathrm{~m}^{2}$ $\left.\mathrm{kg}^{-1}\right)$ and DIS pyrrhotite $\left(\sim 8.9 \mathrm{~A} \mathrm{~m}^{2} \mathrm{~kg}^{-1}\right)$. The EGI figures have to be regarded as somewhat approximate because of the large influence of the magnetite present in these fractions (cf., Table III) on the pyrrhotite $J_{\mathrm{s}}$ determination (1\% difference in magnetite weight percentage leads to a change 
TABLE IV

Some rock-magnetic parameters for natural pyrrhotite

\begin{tabular}{|c|c|c|c|c|c|c|c|c|}
\hline $\begin{array}{l}\text { Grain-size } \\
\text { fraction }\end{array}$ & $\begin{array}{l}X_{\mathrm{in}} \\
\left(\mathrm{m}^{3} \mathrm{~kg}^{-1} \times 10^{-5}\right)\end{array}$ & $\begin{array}{l}H_{\mathrm{c}} \\
\left(\mathrm{kA} \mathrm{m}^{-1}\right)\end{array}$ & $\begin{array}{l}H_{\mathrm{cr}} \\
\left(\mathrm{kA} \mathrm{m}^{-1}\right)\end{array}$ & $\begin{array}{l}H_{\mathrm{cr}^{\prime}} \\
\left(\mathrm{kA} \mathrm{m}^{-1}\right)\end{array}$ & $\begin{array}{l}J_{\mathrm{rs}} \\
\left(\mathrm{A} \mathrm{\textrm {m } ^ { 2 }}\right.\end{array}$ & $\left.\mathrm{g}^{-1}\right)$ & $\begin{array}{l}J_{\mathrm{s}} \\
(\mathrm{A} \mathrm{m}\end{array}$ & $\left.\mathrm{kg}^{-1}\right)$ \\
\hline TTE $250-150$ & 6.15 & 7.78 & 7.96 & 13.05 & 2.04 & & 9.2 & \\
\hline TTE $150-100$ & 6.75 & 8.49 & 9.55 & 14.80 & 3.40 & & 14.2 & \\
\hline TTE 100-75 & 6.24 & 10.02 & 10.74 & 17.82 & 3.89 & & 13.7 & \\
\hline TTE $75-55$ & 5.93 & 12.41 & 12.34 & 21.96 & 4.46 & & 17.0 & \\
\hline TTE 55-40 & 3.86 & 15.60 & 17.51 & 21.01 & 5.00 & & 17.1 & \\
\hline TTE $40-30$ & 4.43 & 20.21 & 22.68 & 29.92 & 5.70 & & 16.2 & \\
\hline TTE $30-25$ & 4.81 & 24.27 & 27.45 & 36.61 & 6.10 & & 16.2 & \\
\hline TTE $25-20$ & 4.45 & 23.08 & 31.04 & 40.58 & 6.47 & & 17.9 & \\
\hline TTE $20-15$ & 4.26 & 30.96 & 34.62 & 43.93 & 6.28 & & 16.4 & \\
\hline TTE $15-10$ & 3.49 & 38.68 & 41.78 & 50.45 & 6.54 & & 16.0 & \\
\hline TTE 10-5 & 2.19 & 49.74 & 51.72 & 60.00 & 4.12 & & 9.3 & \\
\hline TTE $<5$ & 1.17 & 68.04 & 70.03 & 73.85 & 2.54 & & 5.4 & \\
\hline EOR 250-150 & 5.76 & 7.77 & 8.75 & 14.08 & 2.58 & & 13.6 & \\
\hline EOR $150-100$ & 4.87 & 9.04 & 10.74 & 19.82 & 2.80 & & 13.1 & \\
\hline EOR $100-75$ & 3.92 & 10.28 & 13.53 & 21.41 & 3.15 & & 12.5 & \\
\hline EOR $75-55$ & 3.03 & 15.36 & 17.51 & 22.92 & 3.46 & & 10.4 & \\
\hline EOR $55-40$ & 2.25 & 20.13 & 21.88 & 29.28 & 3.81 & & 10.1 & \\
\hline EOR 40-30 & 1.88 & 23.87 & 28.25 & 34.62 & 4.58 & & 16.7 & \\
\hline EOR $30-25$ & 1.17 & 32.71 & 33.02 & 41.38 & 5.25 & & 12.1 & \\
\hline EOR $25-20$ & 1.15 & 35.17 & 36.61 & 45.12 & 4.55 & & 10.8 & \\
\hline EOR 20-15 & 1.11 & 36.05 & 37.40 & 44.17 & 4.86 & & 10.8 & \\
\hline EOR $15-10$ & 0.94 & 45.76 & 46.95 & 55.23 & 4.95 & & 10.8 & \\
\hline EOR $10-5$ & 0.99 & 57.69 & 60.08 & 66.53 & 4.64 & & 10.4 & \\
\hline EOR $<5$ & 0.57 & 77.35 & 83.16 & 67.88 & 1.51 & & 3.5 & \\
\hline EGI $250-150$ & 25.08 & 6.00 & 12.34 & 21.17 & 2.28 & 2.48 & 31.4 & 12.9 \\
\hline EGI $150-100$ & 24.83 & 6.45 & 13.13 & 22.20 & 2.39 & 2.78 & 31.5 & 13.1 \\
\hline EGI 100-75 & 23.70 & 7.96 & 15.52 & 23.95 & 2.82 & 3.25 & 31.4 & 14.9 \\
\hline EGI $75-55$ & 21.33 & 8.75 & 18.30 & 27.14 & 3.11 & 3.54 & 28.8 & 12.6 \\
\hline EGI $55-40$ & 18.22 & 11.70 & 21.09 & 29.68 & 4.09 & 4.76 & 27.1 & 10.4 \\
\hline EGI 40-30 & 15.22 & 14.72 & 26.66 & 35.81 & 4.55 & 5.03 & 24.5 & 12.5 \\
\hline EGI $30-25$ & 13.55 & 17.43 & 27.85 & 37.64 & 4.98 & 5.44 & 23.8 & 11.6 \\
\hline EGI $25-20$ & 13.19 & 18.30 & 29.44 & 38.04 & 4.97 & 5.48 & 23.4 & 8.8 \\
\hline EGI 20-15 & 11.27 & 21.41 & 32.23 & 40.35 & 5.65 & 5.89 & 23.4 & 16.8 \\
\hline EGI $15-10$ & 9.04 & 28.17 & 39.79 & 46.31 & 6.19 & 6.40 & 21.3 & 13.7 \\
\hline EGI $10-5$ & 6.22 & 39.79 & 53.72 & 60.00 & 6.28 & 6.27 & 18.2 & 11.9 \\
\hline $\mathrm{EGI}<5$ & 3.10 & 54.27 & 74.01 & 80.77 & 3.89 & 3.43 & 10.5 & 5.9 \\
\hline DIS $250-150$ & 3.45 & 21.04 & 31.43 & 33.26 & 2.49 & & 7.9 & \\
\hline DIS $150-100$ & 2.30 & 26.45 & 33.02 & 33.02 & 1.78 & & 5.9 & \\
\hline DIS $100-75$ & 2.40 & 23.00 & 33.02 & 37.64 & 1.60 & & 6.6 & \\
\hline DIS 75-55 & 3.49 & 21.41 & 31.51 & 37.00 & 2.35 & & 6.9 & \\
\hline DIS 55-40 & 3.85 & 20.37 & 30.80 & 38.83 & 2.36 & & 9.0 & \\
\hline DIS $40-30$ & 3.52 & 20.93 & 32.71 & 40.58 & 2.64 & & 9.6 & \\
\hline DIS $30-25$ & 4.25 & 21.88 & 31.83 & 39.63 & 3.76 & & 11.8 & \\
\hline DIS $25-20$ & 4.08 & 21.88 & 31.99 & 39.39 & 4.18 & & 11.0 & \\
\hline DIS $20-15$ & 3.09 & 28.17 & 35.41 & 47.75 & 3.86 & & 11.4 & \\
\hline DIS $15-10$ & 2.50 & 34.06 & 44.96 & 54.83 & 3.31 & & 9.8 & \\
\hline DIS $10-5$ & 1.54 & 43.13 & 58.89 & 67.32 & 2.53 & & 7.3 & \\
\hline DIS $<5$ & 1.04 & 57.46 & 75.60 & 72.42 & 1.81 & & 4.9 & \\
\hline
\end{tabular}

The second columns of $J_{\mathrm{rs}}$ and $J_{\mathrm{s}}$ of the EGI fractions refer to the specific parameters corrected for the magnetite content of each fraction (cf., Table III). The $J_{\mathrm{s}}$ corrected figures in particular are prone to a rather large error (the scatter in the individual values for each fraction is rather large) due to the fact that a $1 \%$ error in the magnetite weight percentage determination leads to an increase (or decrease) of $-1 \mathrm{~A} \mathrm{~m}^{2} \mathrm{~kg}^{-1}$ in the 'magnetic corrected' pyrrhotite $J_{\mathrm{s}}$ figures. The magnetite impact on the correction of $J_{\mathrm{rs}}$ is considerably less, because the saturation remanence of magnetite and pyrrhotite per unit mass are of the same order. 


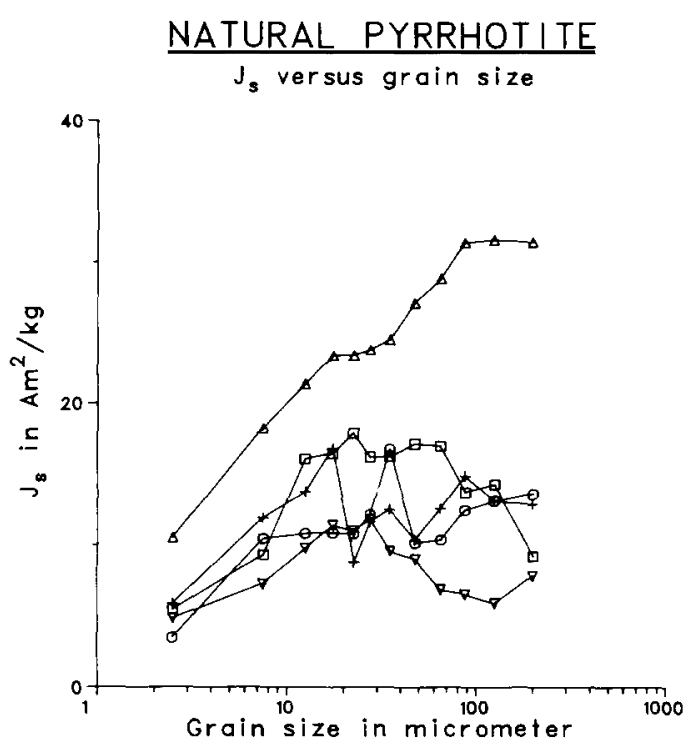

Fig. 3. $J_{\mathrm{s}}$ versus grain size. For symbol meanings see Fig. 2. The magnetite correction in the EGI fractions is based on a saturation magnetization of $90 \mathrm{~A} \mathrm{~m}^{2} \mathrm{~kg}^{-1}$ for magnetite. The magnetite corrected EGI figures are indicated by + . The corrected figures have to be regarded as somewhat approximate because $1 \%$ error in magnetite weight percentage leads to a change in pyrrhotite saturation magnetization of $\sim 1 \mathrm{~A} \mathrm{~m}^{2}$ $\mathrm{kg}^{-1}$.

of $\sim 1 \mathrm{~A} \mathrm{~m}^{2} \mathrm{~kg}^{-1}$ in the corresponding pyrrhotite $J_{\mathrm{s}}$ ). Mark the impact of only $5.5 \mathrm{wt} \%$ magnetite on the corrected pyrrhotite $J_{s}$ figure for the smallest EGI fraction (Table IV).

The $J_{\mathrm{s}}$ trend corresponds well with the compositions indicated by the microprobe analysis (Table IA). The most Fe-deficient pyrrhotite has the highest saturation magnetization. Fluctuation in $J_{\mathrm{s}}$ values of the same pyrrhotite could be caused, apart from errors inherent in the $J_{\mathrm{s}}$ determination procedure (estimation of the magnetite amount in the EGI fractions, estimation of the pyrrhotite amount occurring intimately intergrown with silicates in the coarse DIS fractions), by minute compositional changes between fractions of the same pyrrhotite samples. The $J_{\mathrm{s}} \mathrm{de}$ crease in the coarsest TTE fractions could be explained in this way. It should be realized that small differences in pyrrhotite chemical composition result in considerable differences in saturation magnetization.
It was tested whether the $J_{\mathrm{s}}$ decrease in the fine grain-size fractions could be related to a change in pyrrhotite composition. This was done with the TTE fractions because the $J_{\mathrm{s}}$ decrease is largest in the TTE pyrrhotite. The six finest fractions were heated in a vacuum $\left(10^{-6} \mathrm{~mm} \mathrm{Hg}\right)$ at $350^{\circ} \mathrm{C}$ and subsequently quenched to obtain monophase hexagonal (high temperature) pyrrhotite. The exact position of the compositional dependent $d_{(102)}$ reflection (single hexagonal reflection at $2.06 \mathrm{~A}$ ) was determined with Philips diffractometer system PW $1700\left(\mathrm{Cu} \mathrm{K} \mathrm{K}_{\alpha}\right.$ rays) at room temperature with $\mathrm{Si}$ as internal standard (the $d=1.9201 \AA$ reflection was used). The position of the $d_{(102)}$ reflection was fitted with the Yund and Hall (1969) calibration curve. The resulting $\mathrm{Fe}$ atom percentages were $46.68,46.54,46.59,46.65,47.05$ and 46.73 respectively for the $30-25,25-20,20-15$, $15-10,10-5$ and $<5 \mu \mathrm{m}$ fractions (the standard deviation of the $\mathrm{X}$-ray method is estimated at 0.06 at.\% Fe by Yund and Hall, 1969). Slight compositional differences exist, and the decrease in $J_{\mathrm{s}}$ in the $10-5 \mu \mathrm{m}$ grain-size fraction may be related to its more Fe-rich composition. The $<5 \mu \mathrm{m}$ fraction with an even lower $J_{\mathrm{s}}$, however, has a composition approaching that determined in the coarser fractions with a much higher $J_{\mathrm{s}}$. The low $J_{\mathrm{s}}$ of the $<5 \mu \mathrm{m}$ fraction can thus not be related to a change in chemical composition.

The coercive force $\left(H_{\mathrm{c}}\right)$ increases with decreasing grain size for all samples (Fig. 4; Table IV). No large differences are observed between the

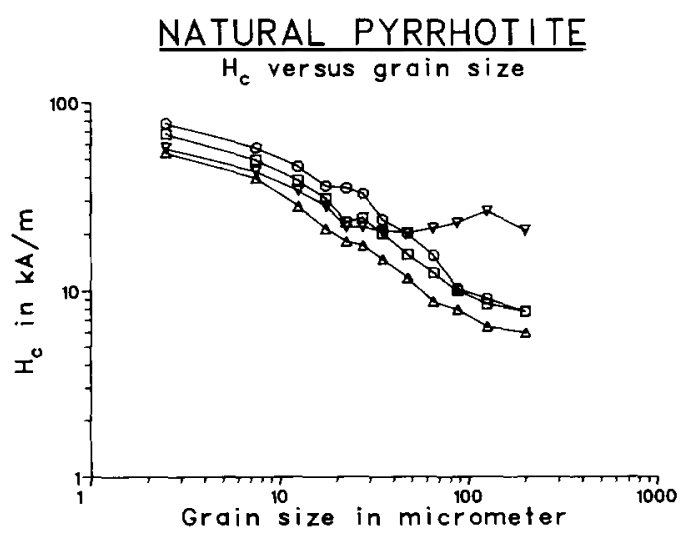

Fig. 4. $H_{\mathrm{c}}$ versus grain size. For symbol meanings see Fig. 2. 
different pyrrhotites. $H_{\mathrm{c}}$ figures derived in the present study concur with Clark's (1984) determinations and for MD grains with the determination of Halgedahl and Fuller (1981). The figures for the PSD range in the present study are somewhat higher than those for this range reported by Soffel (1981). $H_{\mathrm{c}}$ is roughly proportional to the logarithm of the grain size throughout the investigated grain-size range. $H_{\mathrm{c}} \propto d^{-0.67}$ is obtained for the present pyrrhotites for grain-size fractions from $5 \mu \mathrm{m}$ upwards, which is in reasonable agreement with Clark's (1984) determination of $H_{\mathrm{c}} \propto d^{-0.79}$ for a similar grain-size range. The nearly constant $H_{\mathrm{c}}$ in the coarse fractions of DIS pyrrhotite is due to the silica intergrowths in these fractions. The $H_{\mathrm{c}}$ trend for the magnetite-bearing

\section{NATURAL PYRRHOTITE}

Remanent Acquisition Curves

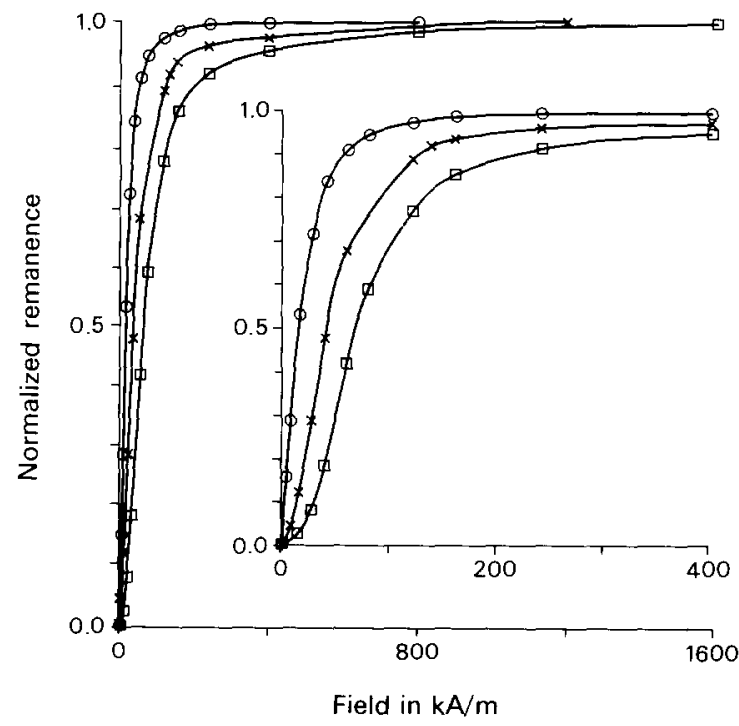

Fig. 5. Examples of acquisition curves of the isothermal remanent magnetization (RA curves) for pyrrhotite normalized to their saturation remanence. Identical grain-size fractions of different pyrrhotite samples revealed identical shapes for their normalized RA curves with coarse grain-size fractions saturating in smaller fields than fine grain-size fractions. O, TTE 150-100 $\mu \mathrm{m}$ fraction, $\square$, DIS $10-5 \mu \mathrm{m}$ fraction, and $\times$, EOR $30-25 \mu \mathrm{m}$ fraction. The inset shows the same RA curves with a $4 \times$ expanded abscissa to display more clearly the differences in grain-size behaviour in small applied fields.

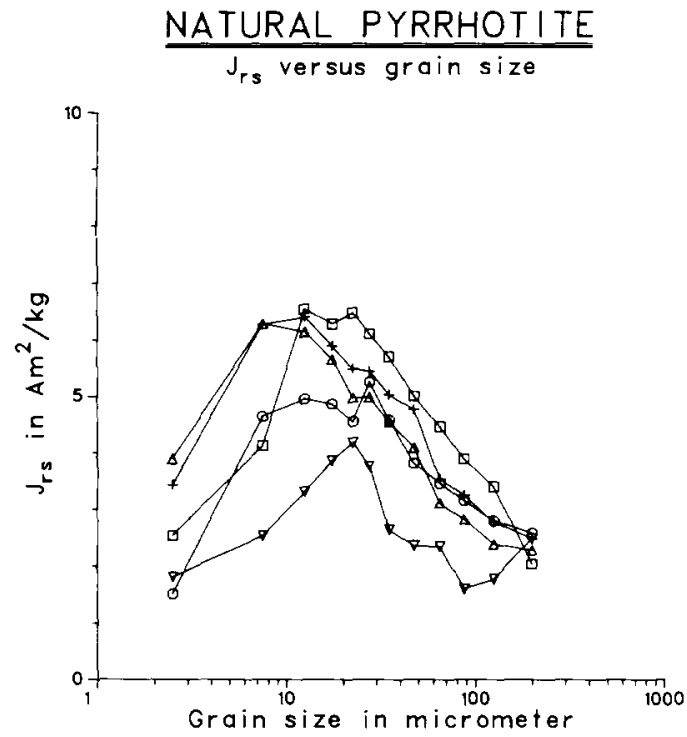

Fig. 6. $J_{\mathrm{rs}}$ versus grain size. For symbol meanings see Fig. 2. The magnetite-corrected $J_{\text {rs }}$ figures for the EGI pyrrhotite fractions are indicated by + . Hartstra's (1982b) magnetite $J_{\text {rs }}$ values were employed because the present magnetite grains underwent similar treatment during the sample preparation procedure. The most Fe-deficient pyrrhotite (TTE) with consequently the highest $J_{\mathrm{s}}$ (Fig. 3) has also the highest $J_{\mathrm{rs}}$. The compositional $J_{\mathrm{s}}$ and $J_{\mathrm{rs}}$ trends are equal.

EGI fractions is below the other curves, because the magnetite $H_{\mathrm{c}}$ is smaller than the pyrrhotite $H_{\mathrm{c}}$ (e.g., Dunlop, 1986; Worm and Markert, 1987; Heider et al., 1987; also for crushed grains, e.g., Day et al., 1977; Hartstra, 1982b).

\subsection{Remanence measurements}

Acquisition curves of the isothermal remanent magnetization (RA curves) are similar for identical grain-size fractions in all samples except for the magnitude of their saturation remanence $\left(J_{\mathrm{rs}}\right)$. The fine grain-size fractions are saturated in larger fields than coarse grain-size fractions (Fig. 5).

$J_{\mathrm{rs}}$ shows a maximum in the $10-30 \mu \mathrm{m}$ range (Fig. 6; Table IV). Absolute figures are somewhat lower than in pure 4C pyrrhotite (Clark, 1984), especially in the fine grain-size range. The trend in $J_{\text {rs }}$ between the samples is the same as the $J_{\mathrm{s}}$ trend: TTE pyrrhotite has the highest $J_{\mathrm{rs}}$, followed in decreasing order by EGI and EOR and finally by DIS. Since $J_{\text {rs }}$ of magnetite (e.g., 


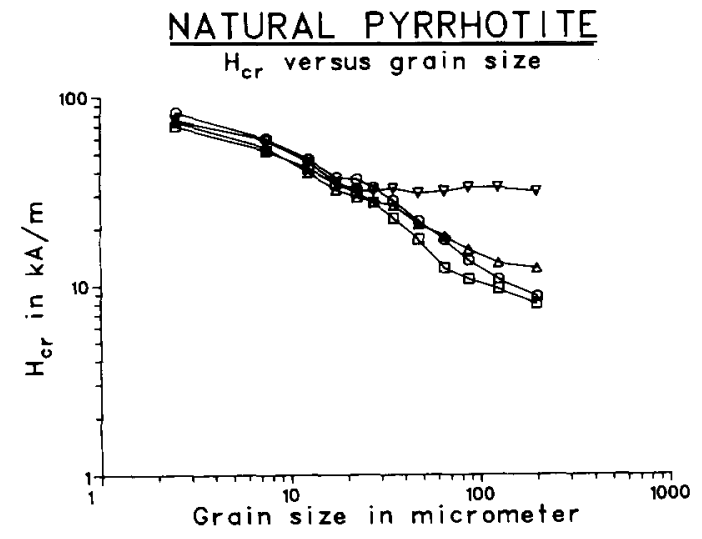

Fig. 7. $H_{\mathrm{cr}}$ versus grain size. For symbol meanings see Fig. 2. Note that the differences between the pyrrhotite samples in $H_{\text {cr }}$ are considerably less than in $H_{\mathrm{c}}$ (Fig. 4).

Hartstra, 1982b) and pyrrhotite are of the same order, the magnetite contribution to the $J_{\mathrm{rs}}$ does not greatly affect the pyrrhotite trend in the EGI fractions (cf., Fig. 6).

The reason for the $J_{\mathrm{rs}}$ decrease in the small grain-size fractions is not known (also observed by Clark (1984) in pure $4 \mathrm{C}$ pyrrhotite, albeit to a lesser extent). In the $<5 \mu \mathrm{m}$ fractions this could partially be due to the presence of superparamagnetic (SP) particles. However, if present, their amount will be subordinate. In the other fractions SP particles will be (virtually) absent, so the reason for the $J_{\mathrm{rs}}$ decline has to be sought elsewhere.

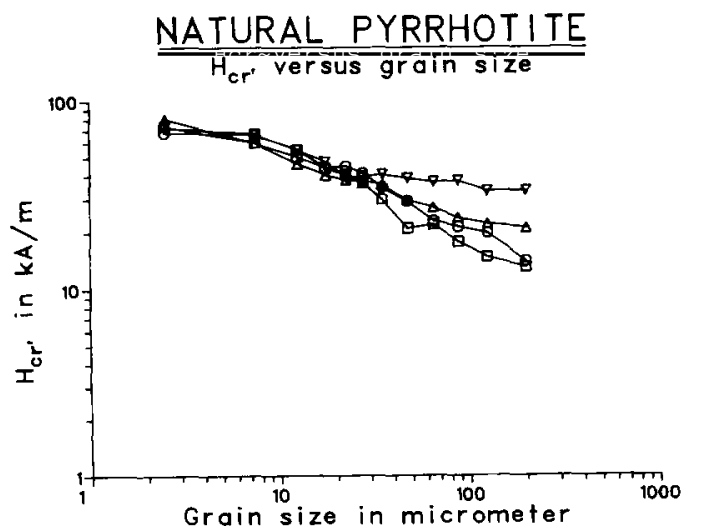

Fig. 8. $H_{\text {cr' }}$ versus grain size. For symbol meanings see Fig. 2. Chemical differences between the pyrrhotites also hardly show up to the $H_{\mathrm{cr}}$, values.
It could be that the domain walls occupy a relatively large part of the grain volume, reducing the effective mass of the grains.

The remanent coercive force $\left(H_{\mathrm{cr}}\right)$ and remanent acquisition coercive force $\left(H_{\mathrm{cr}^{\prime}}\right)$ both increase with decreasing grain size (Figs. 7 and 8). $H_{\text {cr }}$ obeys a $\propto d^{-0.66}$ relationship and $H_{\text {cr' }}$ is proportional to $d^{-0.47}$ for grain-size fractions upwards from the $<5 \mu \mathrm{m}$ fractions. The differences between the different pyrrhotite samples are much smaller than in the $H_{\mathrm{c}}$ plot (Fig. 4). The $H_{\mathrm{cr}}$ and $H_{\text {cr' }}$ figures derived by Clark (1984) are somewhat larger than those determined in the present study. This could be due to the presence of harder finegrained particles in Clark's grain-size fractions. The presence of magnetite hardly shows up in the $H_{\text {cr }}$ and $H_{\text {cr' }}$ trends of the EGI fractions. The constant $H_{\mathrm{cr}}$ and to a lesser extent $H_{\mathrm{cr}}$ ' in the coarse fractions of the DIS sample can be attributed to the presence of silicate intergrowths. The true SD region is not yet reached in the $<5 \mu \mathrm{m}$ fractions, since $H_{\mathrm{c}}$ and $H_{\mathrm{cr}}$ both still increase with respect to the $10-5 \mu \mathrm{m}$ fractions, albeit slightly less than would follow from the $\propto d^{-n}$ relationships. This concurs with the determinations of
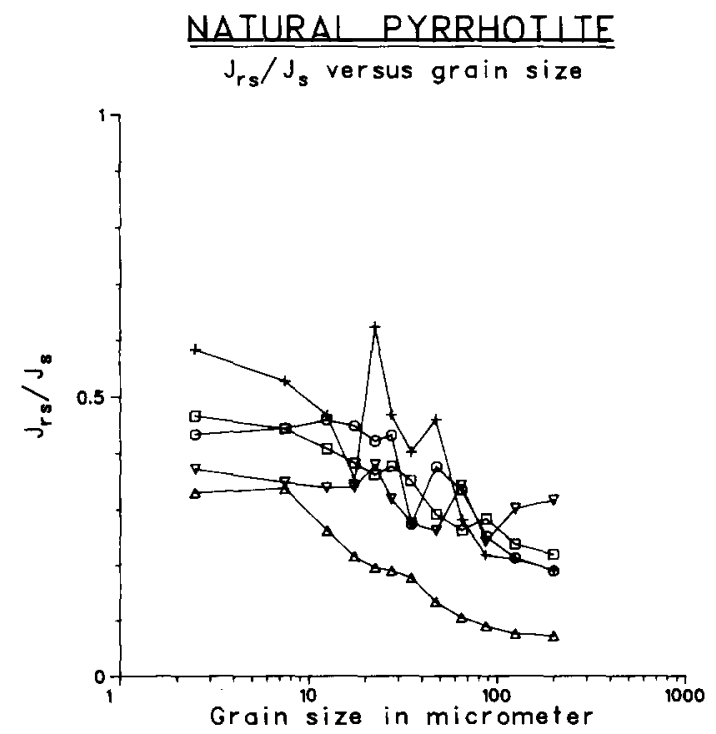

Fig. 9. $J_{\mathrm{rs}} / J_{\mathrm{s}}$ versus grain size. For symbol meanings see Fig. 2. 
TABLE V

Ratios of some pyrrhotite rock-magnetic parameters

\begin{tabular}{|c|c|c|c|c|c|c|}
\hline & $H_{\mathrm{c}} / H_{\mathrm{cr}}$ & $H_{\mathrm{cr}} / H_{\mathrm{cr}^{\prime}}$ & $J_{\mathrm{rs}} / J_{\mathrm{s}}$ & & $\begin{array}{l}J_{\mathrm{rs}} / X_{\mathrm{in}} \\
\left(\mathrm{kA} \mathrm{m}^{-1}\right)\end{array}$ & $\left(J_{\mathrm{rs}} / X_{\mathrm{in}}\right) / H_{\mathrm{cr}}$ \\
\hline TTE 250-150 & 0.98 & 0.61 & 0.22 & & 33.17 & 4.17 \\
\hline TTE $150-100$ & 0.89 & 0.64 & 0.24 & & 50.37 & 5.27 \\
\hline TTE 100-75 & 0.93 & 0.60 & 0.28 & & 62.34 & 5.80 \\
\hline TTE 75-55 & 1.01 & 0.56 & 0.26 & & 75.21 & 6.10 \\
\hline TTE $55-40$ & 0.89 & 0.83 & 0.29 & & 129.53 & 7.40 \\
\hline TTE $40-30$ & 0.89 & 0.76 & 0.35 & & 128.67 & 5.67 \\
\hline TTE $30-25$ & 0.88 & 0.75 & 0.38 & & 126.82 & 4.62 \\
\hline TTE $25-20$ & 0.74 & 0.76 & 0.36 & & 145.39 & 4.68 \\
\hline TTE $20-15$ & 0.89 & 0.79 & 0.38 & & 147.42 & 4.26 \\
\hline TTE $15-10$ & 0.93 & 0.83 & 0.41 & & 187.39 & 4.48 \\
\hline TTE $10-5$ & 0.96 & 0.86 & 0.44 & & 188.13 & 3.64 \\
\hline TTE $<5$ & 0.97 & 0.95 & 0.47 & & 217.09 & 3.10 \\
\hline EOR $250-150$ & 0.89 & 0.62 & 0.19 & & 44.79 & 5.12 \\
\hline EOR $150-100$ & 0.84 & 0.54 & 0.21 & & 57.50 & 5.35 \\
\hline EOR $100-75$ & 0.76 & 0.63 & 0.25 & & 80.36 & 5.94 \\
\hline EOR $75-55$ & 0.88 & 0.76 & 0.33 & & 114.19 & 6.52 \\
\hline EOR $55-40$ & 0.92 & 0.75 & 0.38 & & 169.33 & 7.74 \\
\hline EOR 40-30 & 0.84 & 0.82 & 0.27 & & 243.62 & 8.62 \\
\hline EOR $30-25$ & 0.99 & 0.80 & 0.43 & & 448.72 & 13.59 \\
\hline EOR $25-20$ & 0.96 & 0.81 & 0.42 & & 395.65 & 10.81 \\
\hline EOR $20-15$ & 0.96 & 0.85 & 0.45 & & 437.84 & 11.71 \\
\hline EOR $15-10$ & 0.98 & 0.85 & 0.46 & & 526.60 & 11.22 \\
\hline EOR 10-5 & 0.96 & 0.90 & 0.44 & & 468.69 & 7.80 \\
\hline $\mathrm{EOR}<5$ & 0.93 & 1.22 & 0.43 & & 264.91 & 3.18 \\
\hline EGI $250-150$ & 0.49 & 0.58 & 0.07 & 0.19 & 9.09 & 0.74 \\
\hline EGI $150-100$ & 0.49 & 0.59 & 0.08 & 0.21 & 9.62 & 0.73 \\
\hline EGI $100-75$ & 0.51 & 0.65 & 0.09 & 0.22 & 11.90 & 0.77 \\
\hline EGI $75-55$ & 0.48 & 0.67 & 0.10 & 0.28 & 14.16 & 0.77 \\
\hline EGI $55-40$ & 0.56 & 0.71 & 0.13 & 0.46 & 19.92 & 0.94 \\
\hline EGI $40-30$ & 0.55 & 0.74 & 0.18 & 0.40 & 28.45 & 1.07 \\
\hline EGI $30-25$ & 0.63 & 0.74 & 0.19 & 0.47 & 33.36 & 1.20 \\
\hline EGI $25-20$ & 0.62 & 0.77 & 0.20 & 0.62 & 34.80 & 1.18 \\
\hline EGI $20-15$ & 0.66 & 0.80 & 0.22 & 0.35 & 44.72 & 1.39 \\
\hline EGI $15-10$ & 0.71 & 0.86 & 0.26 & 0.47 & 62.06 & 1.56 \\
\hline EGI $10-5$ & 0.74 & 0.89 & 0.34 & 0.53 & 98.71 & 1.84 \\
\hline $\mathrm{EGI}<5$ & 0.73 & 0.92 & 0.33 & 0.58 & 111.94 & 1.51 \\
\hline DIS $250-150$ & 0.67 & 0.94 & 0.32 & & 72.17 & 2.30 \\
\hline DIS $150-100$ & 0.80 & 1.00 & 0.30 & & 77.39 & 2.34 \\
\hline DIS $100-75$ & 0.70 & 0.88 & 0.24 & & 66.67 & 2.02 \\
\hline DIS 75-55 & 0.68 & 0.85 & 0.34 & & 67.34 & 2.14 \\
\hline DIS $55-40$ & 0.66 & 0.79 & 0.26 & & 61.30 & 1.99 \\
\hline DIS $40-30$ & 0.64 & 0.81 & 0.28 & & 75.00 & 2.29 \\
\hline DIS $30-25$ & 0.69 & 0.80 & 0.32 & & 88.47 & 2.78 \\
\hline DIS $25-20$ & 0.68 & 0.81 & 0.38 & & 102.56 & 3.20 \\
\hline DIS $20-15$ & 0.80 & 0.74 & 0.34 & & 124.92 & 3.53 \\
\hline DIS $15-10$ & 0.76 & 0.82 & 0.34 & & 132.40 & 2.94 \\
\hline DIS $10-5$ & 0.73 & 0.88 & 0.35 & & 164.29 & 2.79 \\
\hline DIS $<5$ & 0.76 & 1.04 & 0.37 & & 174.04 & 2.30 \\
\hline
\end{tabular}

The second $J_{\mathrm{rs}} / J_{\mathrm{s}}$ column for the EGI fractions refers to the magnetite-corrected saturation magnetization/saturation remanence ratio. Owing to uncertainties in the magnetite percentage leading to relatively large errors in the pyrrhotite $J_{\mathrm{s}}$ in particular, the 'magnetite corrected' $J_{\mathrm{rs}} / J_{\mathrm{s}}$ ratios have to be regarded as somewhat approximate. The fluctuations in the ratio superposed upon an increasing trend with decreasing grain size are due to (small) errors in the magnetite weight percentage determination. 
the pyrrhotite SD threshold size at $1.5-2.0 \mu \mathrm{m}$ (Soffel, 1977) or at $3 \mu \mathrm{m}$ (Clark, 1984).

\section{Discussion}

\subsection{Ratios of some rock-magnetic parameters}

The $J_{\mathrm{rs}} / J_{\mathrm{s}}$ ratio is increasing with decreasing grain size from $\sim 0.2$ to close to 0.5 (Fig. 9; Table $\mathrm{V})$. The magnetite influence in the EGI fractions shows up in their lower uncorrected $J_{\mathrm{rs}} / J_{\mathrm{s}}$ ratio. The spreading in the ratios for the corrected EGI fractions is related to their $J_{\mathrm{s}}$ correction for magnetite which is very sensitive for small errors in the determination of the magnetite content. The nearly constant ratios for the coarse DIS fractions again are due to silicate intergrowths.

The $J_{\mathrm{rs}} / J_{\mathrm{s}}$ ratio of 0.14 determined by Halgedahl and Fuller (1981) for large polycrystalline pyrrhotite crystals concurs with the trend indicated by the present pyrrhotites. Clark's (1984) $J_{\mathrm{rs}} / J_{\mathrm{s}}$ ratios for the coarse grain-size fractions are in good agreement with the present determinations; his figures for the fine grain-size fractions are slightly larger. The increase in $J_{\mathrm{rs}} / J_{\mathrm{s}}$ ratio tends to slow down from some $25 \mu \mathrm{m}$ downwards for EOR and DIS pyrrhotite. The ratios obtained for the $<5 \mu \mathrm{m}$ fractions are distinctly lower than the model ratio of 0.75 for SD grains (Dunlop, 1971). This is also observed by Clark (1984). Apparently, one of the easy axes is dominating, resulting in a uniaxial behaviour. The observation of Bin and Pauthenet (1963), who found six easy directions in the basal plane with one axis dominating, points also in this direction.

The $H_{\mathrm{c}} / H_{\mathrm{cr}}$ ratio is remarkably close to unity for the TTE and EOR grain-size fractions; it displays no grain-size dependent trend (Fig. 10; Table V). For the DIS fractions the ratio is smaller $(\sim 0.7)$. The magnetite-bearing EGI fractions have lower $H_{\mathrm{c}} / H_{\mathrm{cr}}$ ratios.

The $H_{\mathrm{cr}} / H_{\mathrm{cr}}$ ratio increases with decreasing grain size from $\sim 0.6$ up to 1.0 (Fig. 11; Table V), an indication that self-demagnetization of $\mathrm{MD}$ grains could play an important role. This $H_{\mathrm{cr}} / H_{\mathrm{cr}}$ ratio is similar for all pyrrhotite samples, since the magnetite content does not emerge in the $H_{\mathrm{cr}}$ and $H_{\text {cr' }}$ trends.

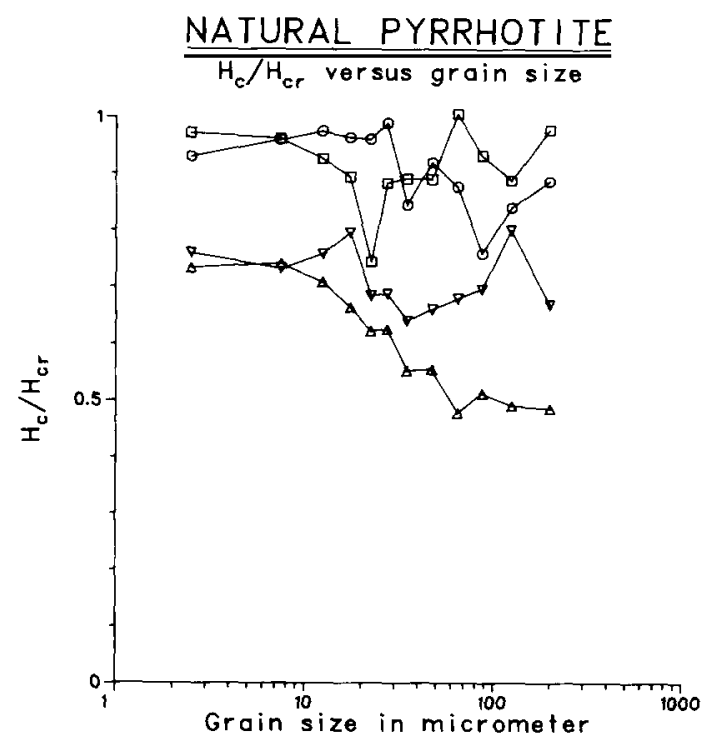

Fig. 10. $H_{\mathrm{c}} / H_{\mathrm{cr}}$ versus grain size. For symbol meanings see Fig. 2. The large figures, which are uniform throughout the investigated grain-size range, make this ratio discriminative between pyrrhotite and magnetite (the EGI ratios are smaller than the others).

The $J_{\mathrm{rs}} / X_{\text {in }}$ ratio increases with decreasing grain size (Fig. 12; Table V); only EOR fractions display high ratios in the intermediate grain-size

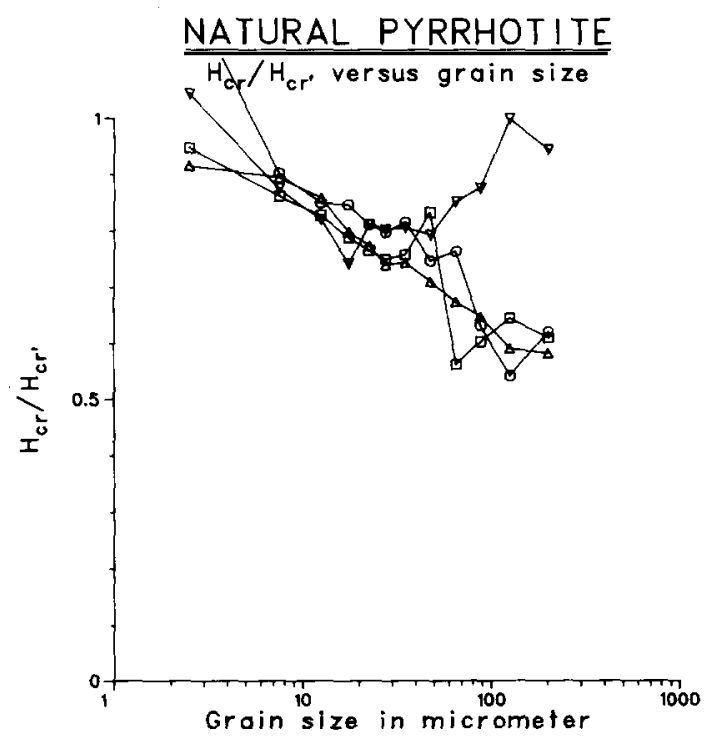

Fig. 11. $H_{\mathrm{cr}} / H_{\mathrm{cr}}$, versus grain size. For symbol meanings see Fig. 2. Its increase with decreasing grain size might be related to self-demagnetization effects which are more pronounced in MD grains. 


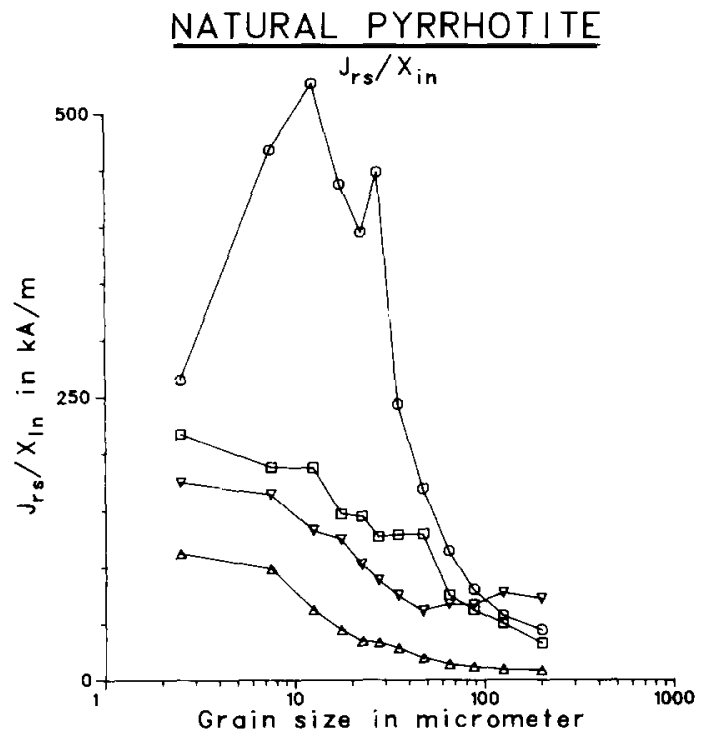

Fig. 12. $J_{\mathrm{rs}} / X_{\text {in }}$ versus grain size. For symbol meanings see Fig. 2. The ratio is larger than $H_{\text {cr }}$ throughout the investigated grain-size interval.

range. The $J_{\mathrm{rs}} / X_{\text {in }}$ ratios are typically larger than $H_{\mathrm{cr}}$ figures for pyrrhotite. $\left(J_{\mathrm{rs}} / X_{\mathrm{in}}\right) / H_{\mathrm{cr}}$ values are larger in $4 \mathrm{C}$-rich pyrrhotite (TTE, EOR) than in more Fe-rich pyrrhotite (DIS, Table V).

\subsection{Comparison of pyrrhotite room-temperature hysteresis parameters with those of magnetite}

The following comparison between pyrrhotite and magnetite rock-magnetic parameters is made using the magnetite data of O'Reilly (1984), Dunlop (1986), Worm and Markert (1987) and Heider et al. (1987). The pyrrhotite saturation magnetization is smaller than that of magnetite whereas the saturation remanence is of the same order (except in the small grain-size fractions, where the magnetite saturation remanence is considerably larger). Pyrrhotite has thus typically higher $J_{\mathrm{rs}} / J_{\mathrm{s}}$ ratios than magnetite, as is demonstrated by the low uncorrected EGI figures (Table V). The pyrrhotite initial susceptibility is considerably smaller than that of magnetite in similar grain-size ranges. Its coercive force is larger than the magnetite coercive force.

For comparison of pyrrhotite remanent coercive force and remanent acquisition coercive force with the same parameters for magnetite, only magnetite data referring to crushed grains are available (e.g., Day et al., 1977; Hartstra, 1982b). The hysteresis properties of such crushed magnetite grains are influenced by stress (e.g., Dunlop, 1986; Heider et al., 1987). No data on $H_{c r}$ and $H_{\mathrm{cr}}$ for large non-crushed magnetite grains have yet been published. $H_{\mathrm{cr}}$ as well as $H_{\mathrm{cr}}$ for pyrrhotite are larger than the respective parameters for magnetite in the fine grain-size fractions and smaller in the coarse grain-size fractions. $H_{\mathrm{cr}}$ and $H_{\mathrm{cr}^{\prime}}$ are more or less equal for both minerals in the $75-55 \mu \mathrm{m}$ range. Since crushing enlarges the magnetite coercive forces, it is reasonable to expect that the parameters for non-crushed magnetite grains will be smaller than those for pyrrhotite throughout the whole investigated grainsize range. Pyrrhotite is thus magnetically 'harder' than magnetite. Titanomagnetite shows, compared with pure magnetite, an increasing hardness with rising $\mathrm{Fe}^{2+}$ content owing to the anisotropic character of the $\mathrm{Fe}^{2+}$ ion. The hardness of pyrrhotite could possibly be explained similarly, because all $\mathrm{Fe}$ in pyrrhotite is considered to be in the divalent state.

The $H_{\mathrm{cr}} / H_{\mathrm{cr}}$, ratio is similar for pyrrhotite and magnetite in the coarse grain-size range, but this ratio increases with decreasing grain size in pyrrhotite whereas it is approximately grain-size independent in magnetite. Typical for pyrrhotite is its high $H_{\mathrm{c}} / H_{\mathrm{cr}}$ ratio, which is approximately uniform throughout the investigated grain-size interval. Another discriminative parameter between pyrrhotite and magnetite is the $J_{\mathrm{rs}} / X_{\mathrm{in}}$ ratio which is considerably larger in pyrrhotite. This ratio is larger than $H_{\text {cr }}$ for pyrrhotite and smaller than $H_{\mathrm{cr}}$ for magnetite.

The presence of pyrrhotite in a sample can thus be established by a high $H_{\mathrm{c}} / H_{\mathrm{cr}}$ ratio or by a $J_{\mathrm{rs}} / X_{\text {in }}$ ratio which is larger than $H_{\mathrm{cr}}$ when it is decided to leave heat treatment of the sample to avoid possible chemical alterations. The pyrrhotite grain-size interval can subsequently be determined by the observed coercive force or, preferably, by the remanent coercive force, because compositional differences in pyrrhotite appear to have only minor influence on its remanent coercive force. 


\subsection{Evaluation of the origin of anisotropy in pyr- rhotite}

The area between the ordinate, the descending branch of the hysteresis loop and the extrapolated line for the determination of the saturation magnetization minus the energy of the demagnetizing field $\left(0.5 N \times J_{\mathrm{s}}^{2}\right)$ represents the reversible magnetization work (e.g., Appel, 1987).

$$
W_{\mathrm{rev}}=\int H \mathrm{~d} J-0.5 N \times J_{\mathrm{s}}^{2}
$$

$\int H \mathrm{~d} J$ can be planimetrically determined. For the present pyrrhotites it appeared that $0.5 N \times J_{\mathrm{s}}^{2}(N$ was set at 0.33 ) constitutes at most a few per cent of $\int H \mathrm{~d} J$ (owing to a relatively low $J_{\mathrm{s}}$ ). Therefore uncertainties regarding the actual value of the demagnetization factor led to negligible error in the $W_{\text {rev }}$ determination.

Anisotropy can have its cause in shape, stress or magnetocrystalline anisotropy. The observed anisotropy can be a mixture of these three contributions. Usually one type of anisotropy is dominating. Neglecting shape anisotropy, it is first assumed that stress anisotropy is dominating. $W_{\text {rev }}$ is then related to the average stress anisotropy energy $\left(E_{\mathrm{sa}}\right)$ by

$W_{\mathrm{rev}}=E_{\mathrm{sa}}=0.75 \lambda \sigma_{\mathrm{i}}$

where $\lambda$ denotes the magnetostriction constant and $\sigma_{i}$ the average internal stress. Soffel (1977) determined a maximum value for the magnetostriction constant of $7 \times 10^{-6}$ for pyrrhotite (the high $\mathrm{Fe}^{2+}$ amount in pyrrhotite apparently does not lead to high magnetostriction constants as in titanomagnetite). Calculation of average internal stress from the present pyrrhotite data yields values between 3500 and $7000 \mathrm{MPa}$, which are unreasonably large. This is demonstrated by the range of 27-63 $\mathrm{MPa}$ for average internal stress in titanomagnetites calculated by Appel (1987) and by a stress of some $200 \mathrm{MPa}$ which is considered reasonable for ceramic materials (cf., O'Reilly, 1984). One may thus conclude that stress is not dominating.

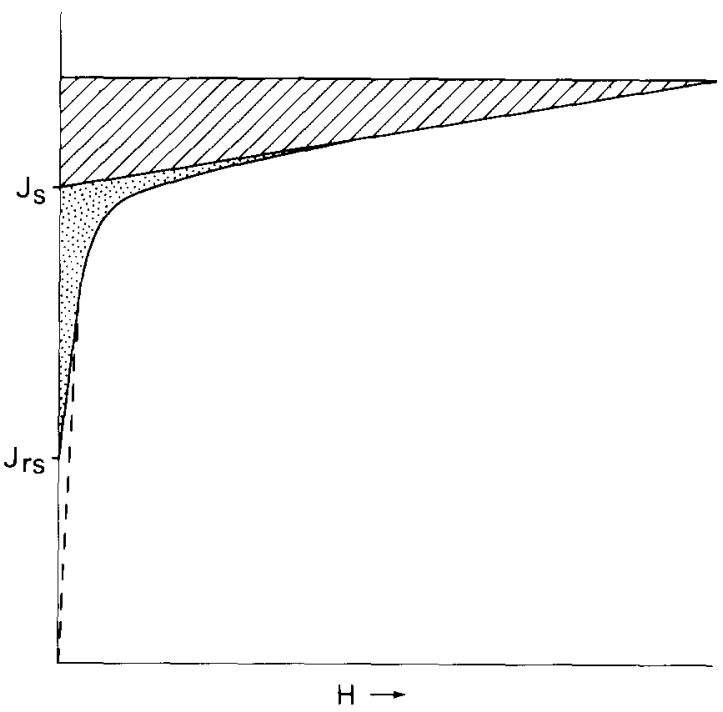

Fig. 13. The stippled area represents $W_{\text {rev }}$; the hatched area represents the minimum work done against the hard axis anisotropy.

The magnetocrystalline anisotropy for pyrrhotite is given by Bin and Pauthenet (1963) as

$$
\begin{aligned}
E_{\text {an }}= & K_{1} \sin ^{2} \theta \sin ^{2} \phi+K_{2} \sin ^{4} \theta \sin ^{4} \phi+K_{3} \cos ^{2} \phi \\
& +K_{4} \cos ^{4} \theta+K_{5} \sin ^{2} \cos ^{2} \theta \sin ^{2} \phi+\ldots
\end{aligned}
$$

$\theta$ is the angle between the magnetization direction and the easy axis. $\phi$ is the angle in the basal plane between an easy axis and the projection of direction of magnetization onto the basal plane. They neglect terms of $K_{5}$ and above. At room temperature $K_{1}$ is $0.35 \times 10^{5} \mathrm{~J} \mathrm{~m}^{-3}, K_{2} \sim 0, K_{3} 1.18 \times 10^{5}$ $\mathrm{J} \mathrm{m}^{-3}$ and $K_{4} 32.2 \times 10^{5} \mathrm{~J} \mathrm{~m}^{-3}$. The large $K_{3}$ and $K_{4}$ are related to the pyrrhotite hard axis of magnetization (measured with applied field parallel to $C$-axis) and $K_{1}$ and $K_{2}$ to basal plane anisotropy. Bin and Pauthenet (1963) note during their measurements six easy directions of magnetization in the basal plane with one axis dominating. They ascribe this to twinning in their pyrrhotite crystal.

Since the reversible work determined for the present pyrrhotites is referring to the energy necessary to overcome basal plane anisotropy (the hard axis behaviour is excluded by the extrapolation to $J_{\mathrm{s}}$ ) and $J_{\mathrm{rs}} / J_{\mathrm{s}}$ ratios of close to 0.5 were found in the smallest pyrrhotite fractions, we treat 
the anisotropy as uniaxial for approximation. $W_{\mathrm{rev}}$ is related to the anisotropy energy $\left(E_{\mathrm{k}}\right)$ as

$$
W_{\mathrm{rev}}=E_{\mathrm{k}}=0.66 K_{\mathrm{an}}
$$

where $K_{\text {an }}$ is the magnetocrystalline anisotropy constant. Calculation yields anisotropy constants in the range of 0.35 up to $0.70 \times 10^{5} \mathrm{~J} \mathrm{~m}^{-3}$ for all pyrrhotites, in fair agreement with the $0.35 \times 10^{5}$ $\mathrm{J} \mathrm{m}^{-3}$ determination of $K_{1}$ by Bin and Pauthenet (1963). The minimum work done against the anisotropy of the hard axis is given by the hatched triangle in Fig. 13. Assuming uniaxial anisotropy for the hard axis, as in Besnus et al. (1968), calculation yields an anisotropy constant range of $5-8 \times 10^{5} \mathrm{~J} \mathrm{~m}^{-3}$ for the hard axis. The range obtained is similar to the anisotropy used by Besnus et al. (1968).

\subsection{Trends in coercive and remanent coercive force}

The present pyrrhotites consist of various intergrown superstructures. Three of the samples (TTE, EOR and EGI) have compositions close 'ideal 4C pyrrhotite' so that the $4 \mathrm{C}$ superstructure is dominating. The fourth (DIS) is a more Fe-rich pyrrhotite which consists apart from the $4 \mathrm{C}$ superstructure of antiferromagnetic NC superstructures. All pyrrhotites show smooth grain-size dependent trends in $H_{\mathrm{c}}, H_{\mathrm{cr}}$ and $H_{\mathrm{cr}}$ (Figs. 4, 7, 8), so apparently the presence of the antiferromagnetic parts does not show up in these trends. It could be that the 'antiferromagnetic' parts carry a kind of defect magnetization (non-integral superstructures) and as such cannot be regarded as nonmagnetic intergrowths. Nakazawa and Morimoto (1971) mention that the 5C, 6C, etc., superstructures are (slightly) ferrimagnetic and not perfectly antiferromagnetic. Soffel (1981) reported the presence of 'pseudo domain walls' which were immobile under the application of an external magnetic field, contrary to normal domain walls which moved due to the same field. He related the presence of pseudo domain walls to minute differences in pyrrhotite superstructure (which he could not make visible by etching).

\section{Conclusions}

The pyrrhotite rock-magnetic parameters, determined in the present study, show smooth grain-size dependent trends. The initial susceptibility is considerably smaller than that of magnetite and decreases with decreasing grain size $\left(7 \times 10^{-5}-1 \times 10^{-5} \mathrm{~m}^{3} \mathrm{~kg}^{-1}\right)$. The susceptibility of the hard axis is $-30-40 \times 10^{-8} \mathrm{~m}^{3} \mathrm{~kg}^{-1}$ for all pyrrhotites. The coercive force, remanent coercive force and remanent acquisition coercive force all increase with decreasing grain size; respectively, 7-80 for $H_{\mathrm{c}}, 8-85$ for $H_{\mathrm{cr}}$ and $14-80$ for $H_{\mathrm{cr}^{\prime}}$ (all in the $\mathrm{kA} \mathrm{m}{ }^{-1}$ ). The coercive forces all obey $d^{--n}$ relationships with grain size above $5 \mu \mathrm{m}$ with $n=0.67$ for $H_{\mathrm{c}}, n=0.66$ for $H_{\mathrm{cr}}$ and $n=0.47$ for $H_{\text {cr' }}$. The pyrrhotite coercive force is larger than the magnetite coercive force; the remanent coercive force and remanent acquisition coercive force are smaller for pyrrhotite than for magnetite in the coarse grain-size fractions whereas the reverse is true in the fine grain-size fractions. The saturation remanence increases with decreasing grain size down to $\sim 30 \mu \mathrm{m}$ and decreases with a further grain-size decrease (increase from 2.0 to $6.0 \mathrm{~A} \mathrm{~m}^{2} \mathrm{~kg}^{-1}$; decrease down to $\sim 2.0 \mathrm{~A}$ $\mathrm{m}^{2} \mathrm{~kg}^{-1}$ ). Its decrease in the fine grain-size range might be related to a relatively large grain volume of domain walls. The saturation magnetization is approximately grain-size independent with a marked decrease for the finest fractions. The reason for this decrease it not known. It varies from - 16.7 $\mathrm{A} \mathrm{m}^{2} \mathrm{~kg}^{-1}$ for TTE via 12.6 for EGI and 11.5 for EOR down to $8.9 \mathrm{~A} \mathrm{~m}^{2} \mathrm{~kg}^{-1}$ for DIS pyrrhotite. The trends indicated by figures for the saturation magnetization and saturation remanence correspond with the equivalent $F e$ trend indicated by the microprobe analysis.

Typical for pyrrhotite are its larger $J_{\mathrm{rs}} / J_{\mathrm{s}}$ ratio ( 0.20 to close to 0.50$)$ and its large $H_{\mathrm{c}} / H_{\mathrm{cr}}$ ratio, which is uniform throughout the investigated grain-size interval $(\sim 0.9$ for relatively $\mathrm{Fe}$-poor pyrrhotite and 0.8 for Fe-richer pyrrhotite). The $H_{\mathrm{cr}} / H_{\mathrm{cr}}$, ratio increases with decreasing grain size, indicative for self-demagnetization of MD grains. The $J_{\mathrm{rs}} / X_{\text {in }}$ ratio is larger than $H_{\mathrm{cr}}$ for pyrrhotite; it increases with decreasing grain size. Calculation of the average internal stress from the reversible 
work given by the reversible part of hysteresis curves yields unreasonably large figures in a range of $3500-7000 \mathrm{MPa}$, so the anisotropy is not dominated by stress anisotropy. Assuming a dominating uniaxial magnetocrystalline anisotropy yields a range of $0.35-0.70 \times 10^{5} \mathrm{~J} \mathrm{~m}^{-3}$ for the anisotropy constant, in fair agreement with the determination of $0.35 \times 10^{5} \mathrm{~J} \mathrm{~m}^{-3}$ of Bin and Pauthenet (1963).

Pyrrhotite and magnetite can be discriminated by the large $J_{\mathrm{rs}} / J_{\mathrm{s}}$ and $H_{\mathrm{c}} / H_{\mathrm{cr}}$ ratios for pyrrhotite and a $J_{\mathrm{rs}} / X_{\text {in }}$ ratio which is larger than $H_{\text {cr }}$ for pyrrhotite. The presence of pyrrhotite in a sample can be established by the $H_{\mathrm{c}} / H_{\mathrm{cr}}$ or the $J_{\text {rs }} / X_{\text {in }}$ ratio; the pyrrhotite grain size can subsequently be derived by the $H_{\mathrm{cr}}$ trend, because pyrrhotite compositional differences appear to have only minor influence on $H_{\mathrm{cr}}$ versus grain-size trend.

\section{Acknowledgements}

Prof. J.D.A. Zijderveld critically reviewed the manuscript. The high-field measurements were carried out at the High Field Magnet Laboratory of the University of Nijmegen (The Netherlands) in co-operation with Dr. J.A.A.J. Perenboom. C.D. Laman (Institute of Earth Sciences, University of Utrecht) made the X-ray films and diffractograms. Trace element determinations were performed by the Service Laboratory (Institute of Earth Sciences, University of Utrecht). This study was supported by the Foundation for Earth Science Research (AWON) of the Netherlands Organization for the Advancement of Pure Research (Z.W.O., grant 751-354-006).

\section{References}

Appel, E., 1987. Stress anisotropy in Ti-rich titanomagnetites. Phys. Earth Planet. Inter., 46: 233-240.

Arnold, R.G., 1967. Range in composition and structure of 82 natural terrestrial pyrrhotites. Can. Mineral., 9: 31-50.

Bertaut, E.F., 1953. Contribution a l'étude des structures lacunaires: la pyrrhotine. Acta Cryst., 6: 557-561.

Besnus, M.J. and Meyer, A.J.P., 1964. Nouvelles données experimentals sur le magnetisme de la pyrrhotine naturelle.
Inst. Phys. \& Phys. Soc., Proc. Int. Conf. Magnetism, Nottingham. pp. 507-511.

Besnus, M.J., Munschy, G. and Meyer, A.J.P., 1968. Sublattice rotations in ferrimagnets: the case of pyrrhotite. J. Appl. Phys., 39: 903-904.

Bigioggero, B., Brigo, L., Ferrario, A., Gergnanin, A., Montrasio, A. and Zuffardi, P., 1979. Strona Valley $(\mathrm{Fe}-\mathrm{Ni}-\mathrm{Cu})$ and $(\mathrm{Fe}-\mathrm{Ba})$ ore deposits: excursion book. Memorie Sci. Geol., 33: 33-39.

Bin, M. and Pauthenet, R., 1963. Magnetic anisotropy in pyrrhotite. J. Appl. Phys., 34: 1161-1162.

Bodechtel, J., 1965. Zur Genese der Eisenerze der Toskana und der Insel Elba. Neues Jb. Mineral. Abh., 103: 147-162.

Bodechtel, J., 1968. Die Paragenesen der Skarnlagerstätten in den Monti di Campiglia/Toskana. Freib. Forsch., H. C231: $7-20$.

Carpenter, R.H., 1974. Pyrrhotite isograde in SE Tennessee and SW North Carolina. Geol. Soc. Am. Bull., 85: 451-456.

Clark, D.A., 1984. Hysteresis properties of sized dispersed monoclinic pyrrhotite grains. Geophys. Res. Lett., 11: 173-176.

Dankers, P.H.M., 1978. Magnetic properties of dispersed natural iron-oxides of known grain-size, Ph.D. thesis, State University of Utrecht, $142 \mathrm{pp}$.

Dankers, P.H.M., 1981. Relationship between median destructive field and remanent coercive forces for dispersed magnetite, titanomagnetite and hematite, Geophys. J. R. Astron. Soc., 64: 447-461.

Day, R., Fuller, M. and Schmidt, V.A., 1977. Hysteresis properties of titanomagnetites: grain size and compositional dependence. Phys. Earth Planet. Inter., 13: 260-267.

Dekkers, M.J., 1988. Some rockmagnetic parameters for natural goethite, pyrrhotite and fine-grained hematite, Ph.D. thesis, State University of Utrecht, $x x i+231 \mathrm{pp}$.

Dekkers, J.M., Hartstra, R.L. and Mullender, T.A.T., in preparation. A device for the magnetite separation of fine particles.

Dimanche, F., 1971. Les minerais de magnétite et les skarns du Ginevro (île d'Elbe, Italie), Mineral. Deposita, 6: 356-379.

Dunlop, D.J., 1971. Magnetic properties of fine particle hematite, Ann. Geophys., 27: 269-293.

Dunlop, D.J., 1986. Hysteresis properties of magnetite and their dependence on particle size: a test of pseudo-singledomain remanence models. J. Geophys. Res., B91: 9569-9584

Ferrario, A., Garuti, G., Rossi, A. and Sighinolfi, G.P., 1983. Petrographic and metallogenic outlines of the "La Balma-M. Capio" ultramafic-mafic body (Ivrea-Verbano Basic Complex, NW Italian Alps). In: H.J. Schneider (Editor), Mineral Deposits of the Alps and of the Alpine Epoch in Europe, Proc. IV ISMIDA 1981, pp. 28-40.

Fleet, M.E. and MacRae, N., 1969. Two phase hexagonal pyrrhotites. Can. Mineral., 9: 699-705.

Freeman, R., 1986. Magnetic mineralogy of pelagic limestones. Geophys. J. R. Astron. Soc., 85: 433-452.

Goodenough, J.B., 1978. Structural chemistry of iron sulfides. Mater. Res. Bull., 13: 1305-1314. 
Halgedahl, S.L. and Fuller, M., 1981. The dependence of magnetic domain structure upon magnetization state in polycrystalline pyrrhotite. Phys. Earth Planet. Inter., 26: 93-97.

Hartstra, R.L., 1982a. Some rock magnetic parameters for natural iron-titanium oxides. Ph.D. thesis, State University of Utrecht, $145 \mathrm{pp}$.

Hartstra, R.L., 1982b. Grain-size dependence of initial susceptibility and saturation magnetization-related parameters of four natural magnetites in the PSD-MD range. Geophys. $J$. R. Astron. Soc., 71: 477-495.

Heider, F., Dunlop, D.J. and Sugiura, N., 1987. Magnetic properties of hydrothermally recrystallized magnetite crystals. Science, 236: 1287-1290.

Kligfield, R. and Channell, J.E.T., 1981. Widespread remagnetization of Helvetic limestones. J. Geophys. Res., B86: 1888-1900.

Mauritsch, H., Becke, M., Kropacek, V., Zelinka, T. and Hejda, P., 1987. Comparison of the hysteresis characteristics of synthetic samples with different magnetite and haematite contents. Phys. Earth Planet. Inter., 46: 93-99.

Morimoto, N., Nakazawa, H., Nishiguchi, K. and Tokonami, M., 1970. Pyrrhotites; stoichiometric compounds with composition $\mathrm{Fe}_{n-1} \mathrm{~S}_{n}$ (n GE 8). Science, 168: 964-966.

Morimoto, N., Nakazawa, H. and Watanabe, E., 1974. Direct observation of metal vacancy in pyrrhotite, $\mathrm{Fe}_{1-x} \mathrm{~S}$, by means of an electron microscope. Proc. Japan Acad., 50: $756-759$.

Morimoto, N., Gyobu, A., Tsukuma, K. and Koto K., 1975a. Superstructure and nonstoichiometry of intermediate pyrrhotite. Am. Mineral. 60: 240-248.

Morimoto, N., Gyobu, A., Mukaiyama, H. and Izawa E., 1975b. Crystallography and stability of pyrrhotites. Econ. Geol., 70: 824-833.

Nakazawa, H. and Morimoto, N., 1971. Phase relations and superstructures of pyrrhotite, $\mathrm{Fe}_{1-x} \mathrm{~S}$. Mater. Res. Bull., 6: $345-358$.

Naldrett, A.J. and Kullerud, G., 1967. A study of the Strathcona mine and its bearing on the origin of the nickel-copper ores of the Sudbury district, Ontario. J. Petrol., 8: 453-534.

Natale, P. and Zucchetti, S., 1979. Remarks on the Fe-Ni-(Cu) deposit of Campello Monti. Memorie Sci. Geol., 33: 213-214.

O'Reilly, W., 1984. Rock and Mineral Magnetism. Blackie, Glasgow, 220 pp.

Pierce, L. and Buseck, P.R., 1974. Electron imaging of pyrrhotite superstructures. Science, 186: 2209-2212.

Rivalenti, G., 1979. Guide to the excursion in the Balmuccia zone, Sesia Valley, Ivrea-Verbano complex. Memorie Sci. Geol., 33: 3-9.

Rochette, P., 1987. Metamorphic control of the magnetic susceptibility of black shales in the Swiss Alps: toward the use of "Magnetic Isogrades". Earth Planet. Sci. Lett., 84: $446-456$.

Schwarz, E.J., 1975. Magnetic properties of pyrrhotite and their use in applied geology and geophysics. Geol. Surv. Can. Paper 74-59: 24 pp.

Schwarz, E.J. and Vaughan, D.J., 1972. Magnetic phase relations of pyrrhotite. J. Geomagn. Geoelectr., 24: 441-458.

Soffel, H.C., 1977. Pseudo-single-domain effects and singledomain multidomain transition in natural pyrrhotite deduced from domain structure observations. J. Geophys., 42: 351-359.

Soffel, H.C., 1981. Domain structure of natural fine-grained pyrrhotite in a rock matrix (diabase). Phys. Earth Planet. Inter., 26: 98-106.

Waldeck, H., 1977. Die Insel Elba-Mineralogie, Geologie, Geographie, Kulturgeschichte, Sammlung geologischer Führer Band 64. Gebr. Borntraeger, Berlin, 169 pp.

Ward, J.C., 1970. The structure and properties of some iron sulphides. Rev. Pure Appl. Chem., 20: 175-206.

Worm, H.-U. and Markert, H., 1987. Magnetic hysteresis properties of fine particle titanomagnetites precipitated in a silicate matrix. Phys. Earth Planet. Inter., 46: 84-92.

Yund, R.A. and Hall, H.T., 1969. Hexagonal and monoclinic pyrrhotites. Econ. Geol., 64: 420-423. 